\title{
Deriving guidelines for the design of plate evaporators in heat pumps using zeotropic
} mixtures

Mancini, Roberta; Zühlsdorf, Benjamin; Jensen, Jonas Kjær; Markussen, Wiebke Brix; Elmegaard, Brian

Published in:

Energy

Link to article, DOI:

10.1016/j.energy.2018.05.026

Publication date:

2018

Document Version

Peer reviewed version

Link back to DTU Orbit

Citation (APA):

Mancini, R., Zühlsdorf, B., Jensen, J. K., Markussen, W. B., \& Elmegaard, B. (2018). Deriving guidelines for the design of plate evaporators in heat pumps using zeotropic mixtures. Energy, 156, 492-508.

https://doi.org/10.1016/j.energy.2018.05.026

\section{General rights}

Copyright and moral rights for the publications made accessible in the public portal are retained by the authors and/or other copyright owners and it is a condition of accessing publications that users recognise and abide by the legal requirements associated with these rights.

- Users may download and print one copy of any publication from the public portal for the purpose of private study or research.

- You may not further distribute the material or use it for any profit-making activity or commercial gain

- You may freely distribute the URL identifying the publication in the public portal 


\section{Accepted Manuscript}

Deriving guidelines for the design of plate evaporators in heat pumps using zeotropic mixtures

Roberta Mancini, Benjamin Zühlsdorf, Jonas Kjær Jensen, Wiebke Brix Markussen, Brian Elmegaard

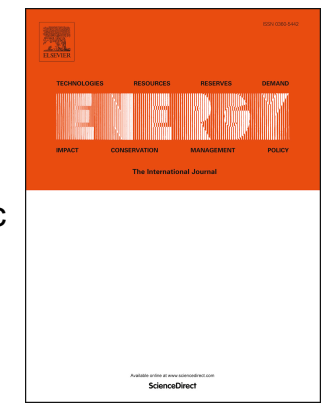

PII:

S0360-5442(18)30846-6

DOI:

10.1016/j.energy.2018.05.026

Reference: $\quad$ EGY 12859

To appear in: Energy

Received Date: 1 December 2017

Revised Date: 25 April 2018

Accepted Date: 3 May 2018

Please cite this article as: Mancini R, Zühlsdorf B, Jensen JonasKjæ, Markussen WB, Elmegaard B, Deriving guidelines for the design of plate evaporators in heat pumps using zeotropic mixtures, Energy (2018), doi: 10.1016/j.energy.2018.05.026.

This is a PDF file of an unedited manuscript that has been accepted for publication. As a service to our customers we are providing this early version of the manuscript. The manuscript will undergo copyediting, typesetting, and review of the resulting proof before it is published in its final form. Please note that during the production process errors may be discovered which could affect the content, and all legal disclaimers that apply to the journal pertain. 


\title{
Deriving guidelines for the design of plate evaporators in heat pumps using zeotropic mixtures
}

\author{
Roberta Mancini $^{\mathrm{a}, *}$, Benjamin Zühlsdorf ${ }^{\mathrm{a}}$, Jonas Kjær Jensen ${ }^{\mathrm{a}}$, Wiebke Brix Markussen ${ }^{\mathrm{a}}$, Brian Elmegaard ${ }^{\mathrm{a}}$ \\ ${ }^{a}$ Technical University of Denmark, Department of Mechanical Engineering, Nils Koppels Allé, Building 403, 2800 Kongens Lyngby, Denmark;
}

\begin{abstract}
This paper presents a derivation of design guidelines for plate heat exchangers used for evaporation of zeotropic mixtures in heat pumps. A mapping of combined heat exchanger and cycle calculations for different combinations of geometrical parameters and working fluids allowed estimating the trade-off between heat transfer area and pressure drops on the thermodynamic and economic performance indicators of the cycle. Compressor running costs constituted the largest cost share, and increased due to a steep decrease of the heat pump coefficient of performance at high refrigerant pressure drops. It was found that the pressure drop limit leading to infeasible designs was dependent on the working fluid, thereby making it impossible to define a guideline based on maximum allowable pressure drops. It was found that economically feasible designs could be obtained by correlating the vapour Reynolds number and the Bond number at the evaporator inlet as $\mathrm{Re}_{\mathrm{V}}^{-0.42} \mathrm{Bd}^{0.26} \approx 0.040$. The use of the proposed guideline was illustrated for the mixture Propane/Iso-Pentane (0.5/0.5), leading to evaporator designs with net present values deviating maximum $-4.4 \%$ from the best value found in the mapping. The presented methodology can be applied in different scenarios to develop similar guidelines, thereby decreasing the cost of combined cycle and component optimizations.
\end{abstract}

Keywords: plate heat exchanger, zeotropic mixture, economic analysis, design guideline, dimensionless numbers, pressure drops, heat transfer area

\section{Introduction}

Zeotropic mixtures are blends of two or more components, with different mass fractions of the liquid and vapour phases at thermodynamic phase equilibrium. Therefore, the temperature at bubble and dew points differ at any saturation pressure and the mixture undergoes a temperature glide during phase change. The use of zeotropic mixtures as working fluids for thermodynamic cycles offers a possibility of optimizing the cycle efficiency by reducing the thermodynamic irreversibility in the heat exchangers (HEXs). Due to non-isothermal evaporation and condensation, the exergy destruction in the HEXs can be reduced by matching the working fluid temperature glide with the heat source and heat sink temperature profiles.

Zühlsdorf et al. [1-3] demonstrated the advantage of using zeotropic mixtures in heat pumps for different applications. A good glide match between the evaporating fluid and the heat source resulted in a beneficial influence on the cycle thermodynamic performance and better improvements were obtained for larger heat source temperature glides [2]. The improvement of using mixtures in a booster heat pump for a district heating system was estimated equal to up $30 \%$ compared to pure working fluids. A larger overall improvement up to $40 \%$ was achieved for a reduced degree of required superheat imposed in the case of mixtures [3].

One drawback of using zeotropic mixtures is the degradation of the heat transfer coefficient compared to pure fluids, which was observed during both evaporation and condensation in different experimental campaigns, as reported in $[4,5]$. In the case of evaporation, several reasons contribute to the heat transfer degradation: (i) an earlier suppression of the nucleate boiling contribution due to an additional mass diffusion resistance created by the more readily

\footnotetext{
* Corresponding author

Email addresses: robman@mek.dtu.dk (Roberta Mancini), bezuhls@mek.dtu.dk (Benjamin Zühlsdorf), jkjje@mek.dtu.dk (Jonas Kjær Jensen), wb@mek.dtu.dk (Wiebke Brix Markussen), be@mek.dtu.dk (Brian Elmegaard)
} 
evaporation of the more volatile component [6,7]; (ii) large variation of the refrigerant physical properties during 20 evaporation, due to variable compositions of liquid and vapour phases, which, according to Jung et al.[8, 9], accounts for the $80 \%$ of the total heat transfer degradation; (iii) worse transport properties of mixtures compared to pure fluids [5]. A number of studies quantified the heat transfer degradation differently: Ross et al. [6] observed a reduction of up to $50 \%$ compared to pure fluids, Jung et al. $[8,9]$ reported varying reduction rates between $19 \%$ and $36 \%$ depending on the mixture composition, while Torikoshi and Ebisu [10] calculated a degradation of $20 \%$ and $30 \%$ compared to the heat transfer coefficient estimated by the ideal mixing rule. It is therefore of paramount importance to optimize the design of the heat transfer equipment when zeotropic mixtures are employed, in order to avoid investing in higher heat transfer areas for the heat exchangers.

Plate Heat Exchangers (PHEs) offer a modular and flexible solution for such applications, since it is possible to achieve high heat transfer coefficients within a compact design due to the flow turbulence generated by the characteristic plate corrugation patterns. PHEs are comprised of thin parallel plates stacked together in order to form channels for fluid flow, which can also be arranged in a counter-current manner for achieving a temperature glide match between the mixture and the secondary fluid. Gasketed-type PHEs consist of plates sealed by gaskets and held together by a frame. For higher operating temperature and pressure, the plates can be sealed together by brazing. At the current state-of-the-art, the operating conditions of gasketed-type PHEs are limited to $20.4 \mathrm{bar}$ and $150{ }^{\circ} \mathrm{C}$, whilst brazed heat exchangers can be operated up to 40 bar $[11,12]$, thereby offering a reasonable range of operation at typical heat pump working conditions.

When designing heat exchangers for a given application, different criteria can be adopted to select the geometrical configuration. The pressure drop of one or both fluids can be limited to a maximum allowable value [11, 12], and the heat transfer area can be minimized for a full utlization of the available pressure loss, as applied in [13]. For single 40 phase HEXs, such pressure drop limitations could also be translated into maximum gas and liquid phase velocities at the inlet, and typical design values can be found in literature for a number of heat exchanger configurations [12]. These values are often based on heuristics from manufacturers and the extension to other types of applications (e.g. zeotropic mixtures and/or phase change) is not trivial.

Following other design approaches, the heat exchanger can be optimized by carrying out a cost minimization 45 problem without a maximum pressure drop limitation, and evaluating the trade-off between heat transfer area and pressure drops. Different previous studies have approached the problem by considering solely the cost related to the heat exchanger, namely the investment cost and the pumping and compression costs related to the two streams, for a general heat exchanger configuration [14, 15], for shell and tube heat exchangers [16] and for plate heat exchangers $[17,18]$. However, the economic analysis lacked assessment of the impact of the heat exchanger pressure drops on 50 the other components, as well as on the overall cycle thermodynamic performance.

In literature a number of studies can be found on simultaneous optimization of plate heat exchangers used as evaporators and/or condensers and thermodynamic cycle design, mostly focusing on low temperature applications and pure fluids. Some of the works are related to the assessment of the impact of some specific cycle parameters on the PHE design [19, 20], whilst other studies performed combined cycle-PHE optimization procedures with the aim 55 of maximizing the cycle efficiency [21], and by including also an economic analysis [22, 23]. The pressure drops were mostly considered as pumping cost on the heat source/sink side, and none of the studies assessed the impact of the working fluid pressure drops on the outlet condition of the evaporator. Moreover, a complete and combined component-cycle optimization comes at a demanding computational cost, especially during the preliminary design phase, where many different working fluids are usually compared and ranked.

The study presented in this paper addresses the following aspects: (i) It presents a methodology for deriving design guidelines for plate heat exchangers integrated in a thermodynamic cycle, namely a heat pump. (ii) The methodology is based on assessing the impact of both plate heat exchanger size and pressure drops on the thermodynamic and economic performance of the heat pump; the pressure losses are not only included as pumping cost of the heat source side, but also imply a modification of the thermodynamic state points of the cycle at the evaporator outlet, which 65 accordingly affects the heat pump design, investment and operating cost. (iii) It utilizes the aforementioned methodology to derive design guidelines for PHE evaporator design in heat pumps using zeotropic mixtures as working fluids. The obtained results are intended for employment in practical engineering during the process of component selection for similar applications, hence avoiding the cost of combined cycle and component analysis.

The methodology is based on complementing a vapour compression heat pump sizing model together with a 70 detailed numerical model of the evaporator, accounting for the variation of the heat transfer coefficient and fluid prop- 
erties during the evaporation process and estimating the impact of heat transfer area and pressure drops on the cycle thermodynamic and economic performance indicators. The methodology was applied to the case of evaporator design for a heat pump, and eight different working fluids were selected based on a previous study [1], which demonstrated the thermodynamic and economic feasibility of using zeotropic mixtures in heat pumps for waste heat recovery in a 75 spray drying facility.

\section{Methods}

The methodology adopted in the present study is based on a parametric analysis on the main design parameters of a plate heat exchanger to assess the impact of the different design configurations on the thermodynamic and economic performance indicators of a thermodynamic cycle, namely a heat pump. Fig.1 shows the schematic of the work flow of the methodology. Two different models were built and integrated in the Matlab environment [24], i.e. a cycle simulation model for a heat pump, explained in details in Section 2.3, and a detailed PHE model, presented in Section 2.4. After the working fluid selection process, explained in Section 2.2, the preliminary sizing of the heat pump was done and the design parameters were calculated, i.e. desired heat exchanger capacity, mass flow rates, pressures and temperatures. The values were subsequently sent to the plate heat exchanger model, which additionally received as inputs the geometrical parameters from which the required heat transfer area and resulting pressure losses were estimated. The outputs were returned to the heat pump model, where the sizing of the cycle was re-evaluated. In this second iteration, the sizing process took into account the resulting heat exchanger size and pressure drops for the economic calculation, as it is briefly described in Section 2.6. The process was repeated for all the combinations of geometrical parameters chosen for the parametric analysis, which is introduced in Section 2.1. Moreover, the same process was repeated for all the eight working fluids considered in the case study, by considering the same combinations of PHE design parameters and calculating the Coefficient of Performance (COP) and Net Present Value (NPV). As shown in Fig.1, all the data points were collected and used as basis for deriving a general design guideline, valid for all the working fluids and the boundary conditions of the present case study. The aim was to correlate the point with optimal economic performances to the PHE design parameters. In order to generalize the results, non95 dimensional parameters were employed as explained in Section 2.8. 


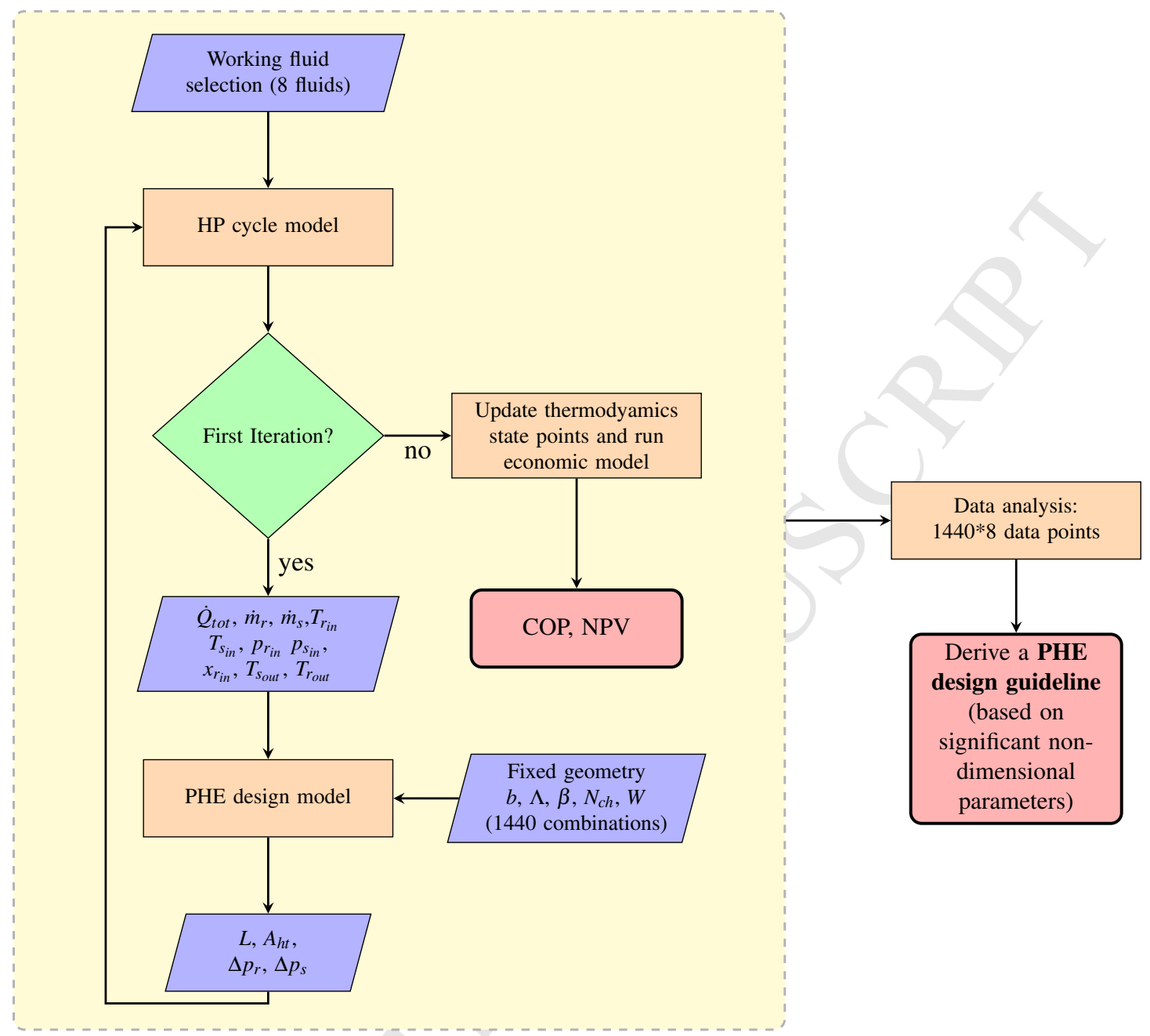

Figure 1: Work flow of the overall methodology

\subsection{Parametric analysis and PHE geometry}

The parametric analysis was carried out by varying the main design variables of a PHE. Fig.2 shows the main geometrical parameters, namely plate size, number and corrugation geometry. The plate size is given by the width $W$ and the length $L ; L_{\mathrm{HT}}$ defines the effective length for heat transfer and the total heat transfer area depends on the number of channels $N_{\mathrm{ch}}$ employed. The corrugation characteristics are determined by the corrugation pitch $\Lambda$, the corrugation height $b$ and the chevron angle $\beta$. The corrugation thickness $t$ is a trade-off between mechanical resistance to stresses and conductive thermal resistance. The corrugation parameters determine the hydraulic diameter of the channels, thereby defining the flow conditions of the working fluid. The hydraulic diameter was estimated by using Eq.(1) [11], where $\Phi$ is the enlargement factor.

$$
D_{h}=\frac{2 b}{\Phi}
$$

The enlargement factor represents the ratio between the actual heat transfer area and the projected area of the plate (without corrugation), and it is expressed by Eq.(2) [11] as function of corrugation height and pitch.

$$
\Phi=\frac{1}{6}\left(1+\sqrt{1+\left(\frac{\pi b}{\Lambda}\right)^{2}}+\sqrt{1+\frac{1}{2}\left(\frac{\pi b}{\Lambda}\right)^{2}}\right)
$$

The port diameter $D_{p}$ determines the inlet/outlet velocities of the refrigerant and the heat source, mainly affecting the port pressure losses; the PHE can be manufactured with different values of the diameter for the two working fluids, 
depending on the desired velocity and the phase.

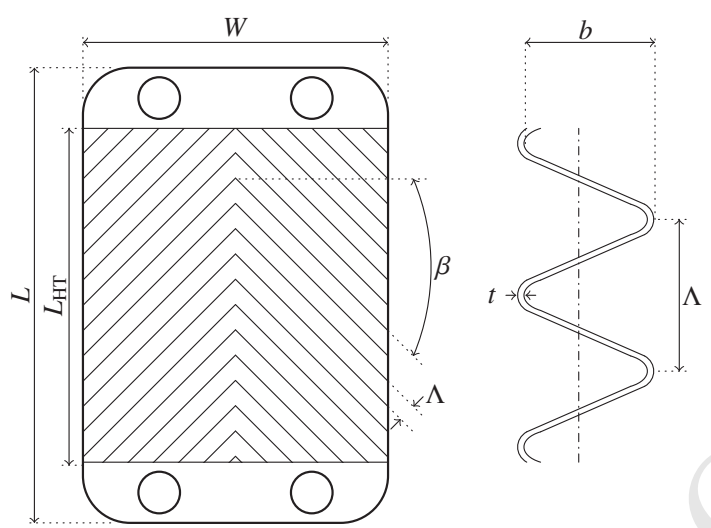

Figure 2: Schematic view of a chevron type PHE [25]

In the parametric study, the design variables were varied among the values reported in Table 1, investigating all the possible combinations between them, for a total of 1440 different PHE configurations. The thickness was fixed to a value commonly found in literature [11]. The port diameter was considered as fixed depending on the magnitude of the plate width. The plate length was calculated as output of the plate heat exchanger design model in order to match the evaporator capacity of the case study for all the combinations of PHE design variables. The plates were considered to be manufactured in stainless steel, with thermal conductivity equal to $16.2 \mathrm{~W} /(\mathrm{m} \mathrm{K})$. The free flow area and the heat transfer area were calculated as function of the design parameters, as reported in Eq.(3) and (4) [11], respectively.

$$
\begin{gathered}
A_{0}=b N_{\mathrm{ch}} W \\
A_{\mathrm{ht}}=2\left(W \cdot L_{\mathrm{HT}}+b \cdot L_{\mathrm{HT}}\right) \cdot N_{\mathrm{ch}} \Phi
\end{gathered}
$$

The effective length $L_{h t}$ was employed for heat transfer calculations, while the port-to-port length was used in order to calculate the frictional pressure losses. The relation between port-to-port length and effective length is given by Eq.(5) [11].

$$
L_{\mathrm{p}}=L_{\mathrm{HT}}+\frac{D_{\mathrm{p}-\text { in }}}{2}+\frac{D_{\mathrm{p}-\text { out }}}{2}
$$

In order to avoid unrealistic results and to minimize maldistribution effects along the plate width, solutions with length to width ratio lower than 2 were considered infeasible and excluded from further analysis.

Table 1: Geometrical parameters of the PHE varied in the parametric study

\begin{tabular}{lcr}
\hline Parameter & Value & Unit \\
\hline$W$ & $0.15,0.25,0.35,0.45,0.55$ & $\mathrm{~m}$ \\
$N_{\mathrm{ch}}$ & $25,50,75,100,150,200$ & - \\
$b$ & $2,4,6,8$ & $\mathrm{~mm}$ \\
$\Lambda$ & $2,4,6,8$ & $\mathrm{~mm}$ \\
$\beta$ & $30,45,60$ & $\circ$ \\
$t$ & 0.5 & $\mathrm{~mm}$ \\
$D_{\mathrm{p}}$ & $0.03,0.06,0.1$ & $\mathrm{~mm}$ \\
\hline
\end{tabular}

\subsection{Case study and working fluid selection}

The framework of the analysis was given by a case study [1] assessing the integration of high temperature heat pumps in a spray drying facility. Waste heat was recovered by integrating a heat pump, with the aim of pre-heating air up to $120^{\circ} \mathrm{C}$. Different zeotropic mixtures were compared in terms of COP and NPV for a single-stage configuration 
of a vapor compression heat pump, in which the working fluid was varied based on binary mixtures formed by combinations of a number of natural refrigerants. The refrigerant screening included hydrocarbons, Dimethyl Ether (DME), Diethyl ether (DEE) and carbon dioxide $\mathrm{CO}_{2}$, chosen for their low Global Warming Potential (GWP) and Ozone Depletion Potential (ODP), and being miscible between each other for wide ranges of temperature and pressure without leading to any chemical reactions $[1,2]$. Table 2 summarizes the best performing mixtures, with considered mass composition and all the evaporation pressures were found to be well below the maximum operating pressure for PHEs. The table also shows the preliminary COP, calculated without accounting for pressure losses of the evaporator.

Table 2: Summary of the considered working fluids

\begin{tabular}{lcc}
\hline Working fluid & $p_{\text {ev }}$, bar & COP, - \\
\hline Propane/Iso-Pentane (0.5/0.5) & 4.9 & 3.08 \\
Propane/n-Pentane (0.8/0.2) & 8.4 & 3.04 \\
Propane/n-Pentane (0.4/0.6) & 3.0 & 3.02 \\
Butane/Hexane $(0.9 / 0.1)$ & 2.5 & 3.07 \\
DME/n-Pentane $(0.4 / 0.6)$ & 2.6 & 3.26 \\
DME/n-Pentane (0.7/0.3) & 5.0 & 3.24 \\
DME/Iso-Pentane $(0.5 / 0.5)$ & 4.0 & 3.15 \\
Propylene/Iso-Pentane (0.4/0.6) & 3.9 & 3.14 \\
\hline
\end{tabular}

\subsection{Heat pump cycle model}

The thermodynamic cycle was modelled in steady state and it consists of a single-stage configuration of a vapour compression heat pump. Fig. 3 shows the sketch of the unit, with the different components integrated in the cycle, namely compressor, condenser, throttling valve and evaporator.

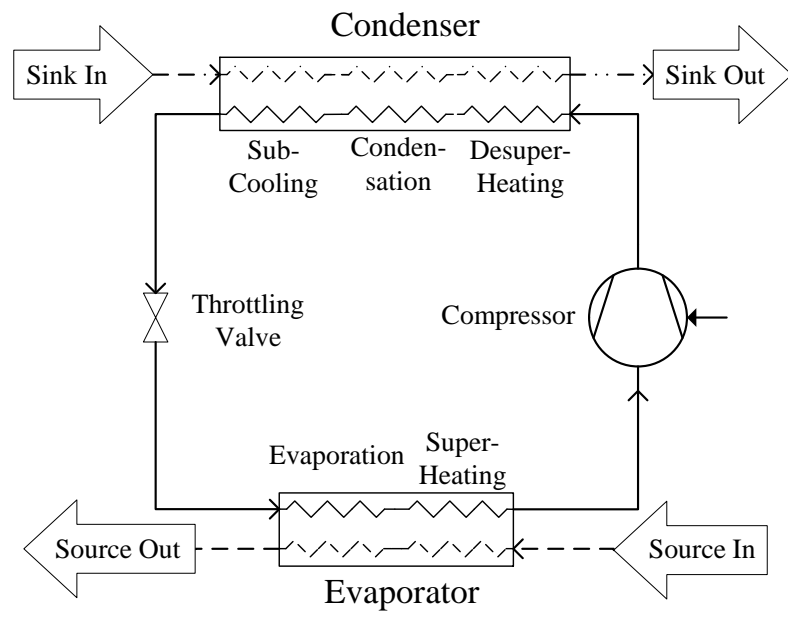

Figure 3: Schematic of the heat pump model

Table 3 shows the design parameters of the cycle. The heat source side was completely defined by the boundary conditions, while the outlet temperature of the condenser was set as a free variable. The evaporation and condensation pressures of the working fluid were defined by the minimum required pinch point temperature difference between the working fluid and the fluid at the secondary side. The amount of subcooling was defined by the pinch point temperature difference and the sink inlet temperature in order to obtain the maximum efficiency. A minimum superheating of $5 \mathrm{~K}$ was included in the evaporator, in order to ensure a dry compression for all the fluids. The compressor was modelled by assuming a constant isentropic efficiency, while the motor efficiency accounted for the power generation losses 
[26]. The thermodynamic performance was evaluated by estimating the COP, defined in Eq.(6), as the ratio between the thermal energy provided to the heat sink and the compressor power.

$$
\mathrm{COP}=\frac{\dot{Q}_{\text {sink }}}{\dot{W}_{\text {comp }}}
$$

The working fluid properties were calculated by Refprop [27], using reccomended standard equation of states and mixing parameters, while heat sink and source properties were computed using CoolProp [28].

Table 3: Boundary conditions for the heat pump

\subsection{PHE design model}

\begin{tabular}{|c|c|c|}
\hline Parameter & Value & Unit \\
\hline \multicolumn{3}{|c|}{ Heat source } \\
\hline Medium & Water & \\
\hline$T_{\text {in }}$ & 65 & C \\
\hline$T_{\text {out }}$ & 40 & C \\
\hline$\dot{m}$ & 14.8 & $\mathrm{~kg} / \mathrm{s}$ \\
\hline$\dot{Q}$ & 1544 & W \\
\hline \multicolumn{3}{|c|}{ Heat sink } \\
\hline Medium & Water & \\
\hline$T_{\text {in }}$ & 75 & \\
\hline$\dot{m}$ & 10.6 & $/ \mathrm{s}$ \\
\hline \multicolumn{3}{|c|}{ Compressor } \\
\hline$\eta_{\text {is }}$ & 0.8 & \\
\hline$\eta_{\text {motor }}$ & 0.95 & \\
\hline$\Delta T_{\mathrm{sh}}$ & 5 & K \\
\hline \multicolumn{3}{|c|}{ Heat exchangers } \\
\hline$\Delta T_{\text {pinch }}$ & 10 & ${ }^{\circ} \mathrm{C}$ \\
\hline
\end{tabular}

The PHE design model was based on a one-dimensional discretization of the heat exchanger along the flow direction, at constant enthalpy steps, hence with constant heat flow rate for each control volume (CV). The heat exchanger solver was based on a successive substitution approach, with heat transfer area and pressure drops set as unknown. A total number of $n=50$ control volumes was chosen, as trade-off between accuracy and computational cost of the design model. The internal solver iterated on the length of each $\mathrm{CV}$, as well as on the pressure drops of both refrigerant and heat source, with a tolerance set on the relative residuals equal to $10^{-2}$.

The PHE model was solved by imposing steady-state mass, momentum and energy conservation equations, which were solved for each CV and both fluids. The logarithmic mean temperature difference method was applied locally, for the computation of the UA value in each CV. Counter-current flow of the refrigerant and heat source was imposed, longitudinal conduction through the walls and heat loss to the external environment were neglected. Thermodynamic state variables and fluid properties were computed for each CV based on a first order linear interpolation of the values at the nodes. The local heat transfer coefficients and pressure drops were estimated using experimental correlations. The choice of appropriate prediction methods for the considered case study is discussed in Section 2.5.

\subsection{Choice of prediction methods}

The local heat transfer coefficient and frictional pressure drops were computed for both fluids using experimental correlations, thereby conveying focus on the choice of suitable prediction methods for the working fluids and the boundary conditions of the case study. Literature presents several correlations developed for the estimation of the heat transfer coefficient for refrigerant flow boiling in PHEs. There is however a lack of a suitable prediction method for the evaporation heat transfer coefficient in PHEs for zeotropic mixtures of natural refrigerants. Amalfi et al. [29] developed a flow boiling correlation based on an extensive database collected from several studies in literature, claiming to have a better agreement than other existing correlations. The only zeotropic mixture included in the database was the near-azeotropic mixture R410a, which presents a small temperature glide during evaporation. Such 
correlation is therefore not directly applicable to the estimation of the heat transfer coefficient of mixtures. Moreover, it does not take the mixture degradation of heat transfer into account.

Mixture degradation of heat transfer was estimated by a number of experimental studies focusing on in-tube flow boiling of different zeotropic mixtures, including ammonia-water. An extensive literature review can be found in [30]. The developed correlations were however derived for tubular geometry, with a different flow mechanism compared to PHEs. In order for a correlation to be fully applicable, the effect of the geometry must be included as well. It was therefore decided to apply a theoretical method, which was first developed for mixture condensation by Silver [31] and Bell-Ghaly [32]. Sardesai et al. [33] extended the theoretical derivation to convective boiling heat transfer, deriving the formulation expressed by Eq.(7) [33].

$$
h_{\mathrm{TP}}=\frac{1+h_{\mathrm{NB}-\mathrm{mix}} / h_{C}}{1 / h_{C}+\bar{z} / h_{V}}
$$

Here, $h_{\mathrm{NB}-\text { mix }}$ is the nucleate boiling contribution of the mixture, $h_{C}$ is the convective two-phase contribution and $h_{V}$ is the single-phase vapour heat transfer coefficient estimated for the vapour flowing alone in the channel. $\bar{z}$ is a correction term taking into account the ratio of sensible over latent heat transfer, and it is evaluated by Eq.(8) [32].

$$
\bar{z}=x \cdot \frac{d T}{d h} \cdot c_{p, V}
$$

In the estimation of $h_{\mathrm{NB}-\mathrm{mix}}$, the mixture effects on degradation of nucleate boiling and loss of effective wall superheat is accounted for by applying a suitable correction factor. Thome and Shakir [34] approach was used for this purpose, expressing the relation between ideal and mixture heat transfer coefficient as [34] :

$$
\frac{h_{\mathrm{NB}-\mathrm{mix}}}{h_{\mathrm{NB}-\mathrm{id}}}=\left\{1+\frac{h_{\mathrm{NB}-\mathrm{id}}}{\dot{Q}^{\prime \prime}}\left(T_{\mathrm{dew}}-T_{\text {bubble }}\right)\left[1-\exp \left(\frac{\dot{Q}^{\prime \prime}}{\rho_{L} h_{\mathrm{lat}} \beta_{L}}\right)\right]\right\}^{-1}
$$

By using the theoretical method proposed by Sardesai [33], it was possible to choose prediction methods specifically developed for chevron-type PHEs for the estimation of the different terms $h_{\mathrm{NB}-\mathrm{id}}, h_{C}$ and $h_{V}$. The method by Amalfi et al.[29] was used to estimate the contribution of convective boiling, while Cooper [35] was employed for the nucleate boiling term. Martin [36] correlation was employed for the single-phase heat transfer coefficient of the vapour flowing alone. The same correlation was used for the refrigerant heat transfer coefficient in the superheated region, as well as for the water single-phase heat transfer coefficient along the whole heat exchanger.

Pressure drops were computed by considering all the contributions to the steady state momentum equation, i.e. friction, gravity(static), acceleration and inlet/outlet ports terms:

$$
\Delta p_{\mathrm{tot}}=\Delta p_{\mathrm{fr}}+\Delta p_{\mathrm{gr}}+\Delta p_{\mathrm{acc}}+\Delta p_{\text {ports }}
$$

The pressure drop over the total length of the HEX was calculated by considering each control volume separately. In the two-phase region, the accelleration and static contributions were calculated by the homogeneous model, thereby using Eq.(11) and Eq.(12) for each CV, respectively [37].

$$
\begin{gathered}
\Delta p_{\mathrm{acc}}=G^{2}\left[\left(\frac{x}{\rho_{V}}+\frac{1-x}{\rho_{L}}\right)_{\mathrm{OUT}}-\left(\frac{x}{\rho_{V}}+\frac{1-x}{\rho_{L}}\right)_{\mathrm{IN}}\right] \\
\Delta p_{\mathrm{gr}}=\rho_{m} g \Delta L
\end{gathered}
$$

The two-phase mean density was determined by:

$$
\rho_{m}=\left[\frac{x}{\rho_{V}}+\frac{1-x}{\rho_{L}}\right]^{-1}
$$

Eq.(13) was also used for the computation of the frictional pressure drop in the two-phase region. The frictional contribution was calculated by means of the two-phase Fanning friction factor, as expressed by Eq.(14) [37].

$$
\Delta p_{\mathrm{fr}}=2 f_{\mathrm{TP}} \frac{\Delta L G^{2}}{D_{h} \rho_{m}}
$$

The friction factor was computed by using the correlation by Amalfi et al. [29]. In the single-phase region, the friction factor correlation by Martin [36] was used for both the refrigerant superheating and the water flow. Last, the port pressure drops were computed using the Shah and Focke [38] correlation, as expressed by Eq.(15), where $G_{p}$ 
indicates the mass flux at the ports, depending on the port diameter.

$$
\Delta p_{\text {ports }}=0.75\left[\left(\frac{G_{p}^{2}}{2 \rho}\right)_{\mathrm{IN}}+\left(\frac{G_{p}^{2}}{2 \rho}\right)_{\mathrm{OUT}}\right]
$$

For the refrigerant flow, port pressure losses were considered only at the outlet control volume, since the inlet loss was included in the refrigerant expansion at the throttling valve. Both inlet and outlet pressure drops due to ports were evaluated for the heat source, thereby contributing to the pumping power.

\subsection{Economic model}

After the sizing of the PHE, the heat pump model was re-evaluated by taking the updated temperature and pressure at the evaporator outlet into account, as shown in Fig.1. Therefore, the COP was slightly affected by the change in compressor power resulting from the mixture pressure drop. Different aspects of the HEX design influenced the value of the NPV of the heat pump. The NPV was calculated by considering different cost and revenue streams, by using Eq.(16) [1]. The considered costs were the Total Capital Investment (TCI), accounting for the Capital Investment (CI) of each system component, the Operation and Maintenance Cost (OMC), the electricity $\operatorname{cost}\left(\mathrm{FC}_{\mathrm{hp}}\right)$ due to the compressor running and the required water pumping cost $\left(\mathrm{FC}_{\mathrm{w}}\right)$. The revenue stream was considered as the natural gas saving $\left(\mathrm{FC}_{\mathrm{ng}}\right)$, which otherwise would be necessary to produce the thermal energy output of the heat pump.

$$
\mathrm{NPV}=-\mathrm{TCI}-\mathrm{OMC}-\frac{\mathrm{FC}_{\mathrm{hp}}}{\mathrm{CRF}}-\frac{\mathrm{FC}_{\mathrm{w}}}{\mathrm{CRF}}+\frac{\mathrm{FC}_{\mathrm{ng}}}{\mathrm{CRF}}
$$

The interest and inflation rates were assumed equal to $7 \%$ and $2 \%$, respectively, and then used for the estimation of the Capital Recovery Factor (CRF), with a plant economic lifetime of 20 years [26] [39]. Operation and Maintenance Costs were assumed to be the $20 \%$ of the investment cost as one time cost at the time of the investment [39]. The saving of natural gas was calculated by estimating the useful thermal energy produced by the heat pump, equal to the heat sink capacity and by considering a boiler efficiency $\eta_{\text {boiler }}$ equal to 0.9 [26]. The price of natural gas was considered as $0.0303 € / \mathrm{kWh}[40]$.

The TCI accounted for the investment of condenser, compressor and evaporator. The sizing of the condenser was carried out by considering constant heat transfer coefficients and by using the logarithmic mean temperature difference methods for the three different sections of desuperheating, condensation and subcooling. The TCI of each individual component was calculated from the Purchased Equipment Cost (PEC), scaled according to the component size with scaling factors and reference values of PECs reported by Ommen et al. [26]. The TCI was increased by a factor 4.16 compared to the PEC, to account for the investment of the expansion of an existing facility [39].

230 The running cost of the compressor, given by $\mathrm{FC}_{\mathrm{hp}}$ was adapted to the updated compressor power by considering an estimation of $7400 \mathrm{hr} / \mathrm{yr}$ [1] as annual operating time $\tau_{h}$ of the heat pump and an electricity cost $c_{\mathrm{el}}$ of $0.0783 € / \mathrm{kWh}$ [40]. The additional fuel cost term due to the water pressure drops, was calculated by using Eq.(17) as a function of the water mass flow rate, water density, total water pressure drops, and a pump efficiency $\eta_{\text {pump }}$ equal to 0.95 .

$$
\mathrm{FC}_{\mathrm{w}}=\frac{\dot{m}_{s}}{\rho_{s}} \frac{\Delta p_{\mathrm{s}-\mathrm{tot}}}{\eta_{\text {pump }}} c_{\mathrm{el}} \tau_{h}
$$

235 Fig.4 shows the $\log (\mathrm{p})$-h diagram of the heat pump with and without pressure drops in the evaporator. It can be noticed how the outlet of the evaporator is affected by the pressure losses, thus changing the compressor power required as well as the investment cost, which is based on the suction line. The pressure drop also influences the evaporator inlet location in the diagram, but to a lower extent compared to the outlet. In order to compare the results for different working fluids, performing with different COP and maximum NPV, it was decided to normalize each NPV for the maximum value calculated for the specific fluid. The value of NPV of a certain design point of the HEX $i$ for a given working fluid wf was therefore normalized as $\mathrm{NPV}_{\mathrm{i}-\mathrm{wf}}^{\star}$, defined by Eq.(18).

$$
\mathrm{NPV}_{\mathrm{i}-\mathrm{wf}}^{*}=\frac{\mathrm{NPV}_{\mathrm{i}-\mathrm{wf}}}{\max \left(\mathrm{NPV}_{\mathrm{wf}}\right)}
$$




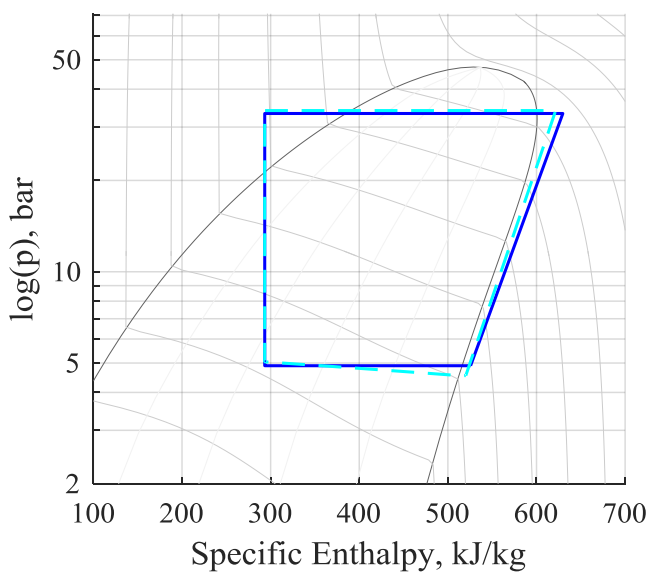

Figure 4: Example of $\log (p)-h$ diagram without pressure drops (blue) and with $50 \mathrm{kPa}$ pressure losses in the evaporator (sky-blue)

\subsection{Data analysis}

The different HEX configurations and working fluids were compared based on dimensionless numbers, in order to derive a guideline describing the design points corresponding to maximum NPV. Non-dimensional parameters were chosen in order to describe the impact of the fluid properties, of the boundary conditions imposed by the cycle (refrigerant evaporation pressure, mass flow and inlet quality) and of the PHE geometry. The main dimensionless numbers governing the heat transfer and pressure drop correlations for the two-phase flow of the mixture were used (see Section 2.4), and they are reported in Table 4.

Table 4: Non-dimensional parameters used for the analysis of the results

\begin{tabular}{ccc}
\hline Symbol & Name & Formula \\
\hline$\theta^{\star}$ & Dimensionless inclination angle & $\frac{90-\beta}{70}$ \\
$\operatorname{Bd}$ & Bond number & $\frac{g D_{h}^{2}\left(\rho_{L}-\rho_{V}\right)}{\sigma}$ \\
$\mathrm{We}_{m}$ & Weber number & $\frac{G^{2} D_{h}}{\sigma \rho_{m}}$ \\
$\rho^{*}$ & Liquid-to-vapour density ratio & $\frac{\rho_{L}}{\rho_{V}}$ \\
$\operatorname{Re}_{\mathrm{LO}}$ & Liquid only Reynolds number & $\frac{G D_{h}}{\mu_{L}}$ \\
$\operatorname{Re}_{V}$ & Vapour alone Reynolds number & $\frac{G x D_{h}}{\mu_{V}}$ \\
\hline
\end{tabular}

The numbers were used to correlate the normalized net present value to the different heat exchanger designs. The parameters were evaluated at the refrigerant conditions at the evaporator inlet, since the scope was to derive guidelines applicable before the actual component design. The inlet conditions are fixed by the boundary conditions 
of the heat pump, thereby being known for all the fluids a priori. It was therefore decided to exclude the Boiling number from the data analysis, since it requires information on the heat flux distribution along the heat exchanger and a preliminary estimation of the heat transfer area is needed. The Weber number $\mathrm{We}_{m}$ is defined by evaluating the equivalent two-phase density, expressed by Eq. 13.

The correlation between the dimensionless parameters and the normalized NPV was obtained by adopting a power law of the form expressed by Eq.(19).

$$
\mathrm{NPV}^{*}=a \cdot \theta^{* b} \cdot \mathrm{Bd}^{c} \cdot \mathrm{We}_{m}^{d} \cdot \operatorname{Re}_{V}^{e} \cdot \operatorname{Re}_{\mathrm{LO}}^{f} \cdot \rho^{* g}
$$

The normalized NPV was first correlated as function of all the dimensionless parameters considered in Table 4. All the design points with positive NPV were considered in the fitting, and the results for all the working fluids were considered simultaneously in one fitting. After deriving the coefficient for Eq. (19), the most relevant parameters were identified. This was done by evaluating the obtained exponent and by comparing different combinations of nondimensional numbers. The correlation that best fitted the NPV trend for all the fluids, as well as leading to a similar optimal range for the different mixtures, was chosen and presented as design guideline.

\subsection{Uncertainty analysis}

For each correlation chosen for the PHE design model, for both heat transfer and pressure drop, a certain accuracy was reported by the authors. This measure represents an estimation of how well the prediction method fits the experimental database from which the correlation was derived. Therefore the accuracy does not necessarily indicate the uncertainty of the prediction methods when they are applied to different working fluids, geometry and operating conditions. It is however relevant to evaluate the change of the obtained results when a certain deviation is applied to the calculation of heat transfer coefficient and pressure drops. For this purpose the accuracy bounds of each correlations were considered as a source of uncertainty in an uncertainty analysis, with the aim of evaluating to which extent the results would change for similar variations in the inputs. The bounds are reported in Table 5, with the exception of $h_{V}$. Since Martin [36] expresses $h_{V}$ as a function of $f_{V}$, the uncertainty of $h_{V}$ was directly included by considering the accuracy bound for the vapour friction factor $f_{V}$.

Table 5: Input uncertainties for the uncertainty analysis

\begin{tabular}{cccc}
\hline Parameter & Correlation & Bounds & Reference \\
\hline$h_{C}$ & Amalfi & $\pm 22.1 \%$ & Mean absolute error [29] \\
$h_{\mathrm{NB}-\mathrm{id}}$ & Cooper & $\pm 59.0 \%$ & Mean absolute error, reported in [37] \\
$\frac{h_{\mathrm{NB}-\text { mix }}}{h_{\mathrm{NB}-\mathrm{id}}}$ & Thome and Shakir & $\pm 11.1 \%$ & Mean absolute error, reported in [41] \\
$f_{\mathrm{TP}}$ & Amalfi & $\pm 21.5 \%$ & Mean absolute error [29] \\
$f_{\mathrm{V}}$ & Martin & $-50.0 \%+100 \%$ & Accuracy bounds, reported in [11] \\
& & & \\
\hline
\end{tabular}

The Monte Carlo (MC) method [42] was applied in order to carry out the uncertainty analysis, with the aim of estimating the probability density of the model outputs, namely $A_{\mathrm{ht}}, \Delta p_{\mathrm{r}, \mathrm{tot}}, \Delta p_{\mathrm{s}, \text { tot }}$ and NPV. The inputs were assumed to be uniformly distributed between the uncertainty bounds reported in Table 5. A latin hypercube sampling (LHS) technique was adopted to create 500 different samples in the input space, proved to be more reliable compared to random sampling [43]. The MC simulations were performed following the approach by Sin and Gernaey [44], and the results were obtained as mean values, standard deviations and $95 \%$ coverage intervals. The analysis was applied to Propane/Iso-Pentane (0.5/0.5), by fixing the PHE geometry to one of the optimal designs found by applying the derived design guideline. 


\section{Results}

In this section, the main results are presented. Sections 3.1 and 3.2 present the trade-off between heat transfer area and pressure drops and the impact on the different revenue and cost streams. Sections 3.3 and 3.4 report the fitting with the non-dimensional parameters and the derivation of the final design guideline.

\subsection{Heat transfer area and pressure drops}

Fig.5 shows the NPV as function of the heat transfer area (a) and total refrigerant pressure drops (b) for all the fluids considered in the analysis. It is shown that both heat transfer area and pressure drops have an impact on the economic performance of the heat pump. However, the NPV decreases to a lower extent for higher values of $A_{\mathrm{ht}}$ compared to an increase of the refrigerant pressure drops. Fig 5(b) shows that for all the eight cases there is a trade-off which coincides with minimizing the refrigerant pressure drops to a very low value. Moreover, Fig 5(b) shows that the pressure drops impact is different depending on the fluid: the mixtures Butane/Hexane (0.9/0.1) and DME/n-Pentane $(0.4 / 0.6)$ are the most sensitive to pressure drops, performing with negative NPVs at $60 \mathrm{kPa}$ and $120 \mathrm{kPa}$, respectively.

On the contrary, Propane/n-Pentane (0.8/0.2) shows a weaker dependence, with NPV values always positive in the considered pressure drop range.

- Pro-iPe $(0.5 / 0.5)$

- Pro-nPe(0.8/0.2)

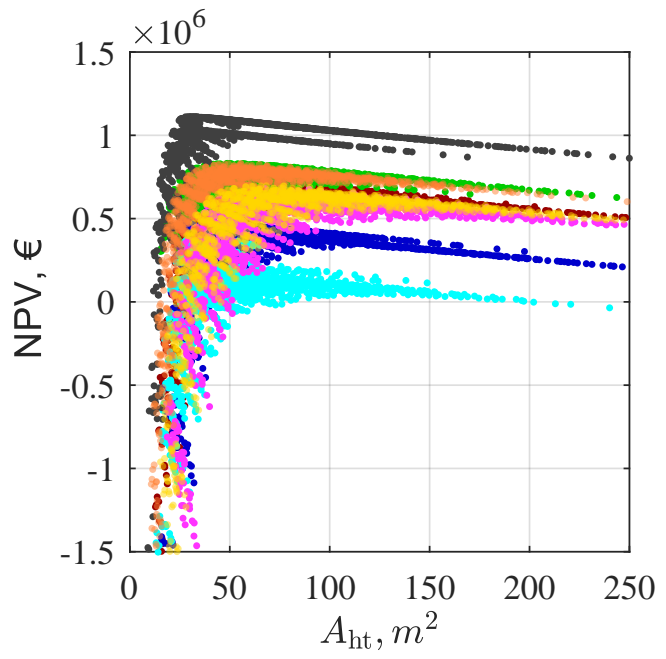

(a)
- Pro-nPe(0.4/0.6)

- But-Hex(0.9/0.1)
- DME-nPe(0.4/0.6)

- DME-nPe(0.7/0.3)
DME-iPe $(0.5 / 0.5)$

Propy-iPe(0.4/0.6)

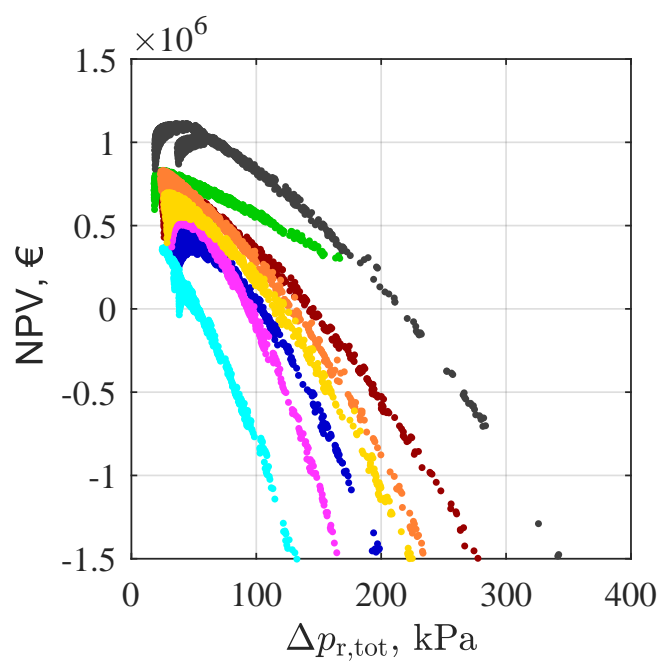

(b)

Figure 5: Effect of heat transfer area of the evaporator (a) and refrigerant total pressure losses (b) on the non-dimensional NPV for all the working fluids

\subsection{Cost breakdown}

Fig.6 shows the breakdown of the NPV as calculated by Eq.16. The abscissa reports the refrigerant total pressure drop, with trends similar for all the working fluids. The blue line indicates the revenue stream, which contributed positively to the NPV and was determined by the natural gas saving. The black line represents the sum of all the expenses, which impacted negatively the NPV. The breakdown of the different terms of the total cost is indicated by the filling colors of the cost line.

The dominant contribution was given by the compressor running cost (grey area), which was negatively affected by the refrigerant pressure drop, causing an increase of the required compressor work. This is explained by Fig.7, 
of the heat pump, a lower COP entails a higher required compressor work, as shown by Eq.(6). A sharp decrease is observed for all the fluids, with different slopes, similarly to the trends found in Fig.5 (b). The different trends for the different fluids found in the cost breakdown of Fig.6 can therefore be explained by a different sensitivity of the COP to the pressure drop. The mixture Propane/n-Pentane $(0.8 / 0.2)$ was found to be least affected by pressure drop, while Butane/Hexane (0.9/0.1) presented the steepest slope.

In the cost breakdown of Fig.6, the TCI is the second highest contribution, indicated by the light-blue area. The TCI undergoes a slight increase for low values of refrigerant pressure drop, and then increases more sharply for higher pressure drop. Since operation and maintenance was considered as a fixed share of the capital investment, OMC undergoes the same trend. An explanation for the TCI behaviour can be found in Fig.8(a) and (b), showing the capital investment of the evaporator, condenser and compressor as functions of the total refrigerant pressure drop. All the working fluids are reported in the same plot with different marker colors. The evaporator and condenser investment costs, directly related to the heat transfer area, are one order of magnitude lower than the compressor investment if the pressure drops are not minimized. When the evaporator investment increases at lower pressure drops (entailing a higher investment due to the larger heat transfer area), the CI of the HEX reaches the same order of magnitude of the lower investment entailed by the compressor. The change in HEX CI due to varying heat transfer area is similar for all the fluids, with an overlap of the different curves.

On the other hand, the compressor CI in Fig.8 (b) undergoes a steep increase for higher values of pressure drop and presents different trends depending on the mixture. The sharp increase is due to the change in the compressor suction line, which is affected by the evaporator outlet. In fact, for higher refrigerant pressure drops, a lower refrigerant outlet density is obtained, entailing a higher volume flow rate, which is directly proportional to the compressor size and cost. The different slopes for the different fluids are related to a different sensitivity of the refrigerant properties to the change in evaporator outlet pressure. The trends of the fluids follow the results found for COP in Fig.7, with Propane/n-Pentane (0.8/0.2) showing the weakest dependence on the pressure drops and opposite trends for mixtures Propane/n-Pentane (0.4/0.6) and Butane/Hexane (0.9/0.1), where the pressure drops have a major influence on both the compressor running cost and TCI.

One very relevant aspect to highlight is the intersection point between revenue and costs streams, in Fig.6, representing the pressure drop limit above which the design of the PHE leads to infeasible solutions, i.e. with negative NPV. This limit value is not the same for all the working fluids, supporting the thesis that it is not necessarily optimal to design HEXs by imposing a maximum allowable pressure drop regardless of the working fluid or boundary conditions.

The water pumping cost was found to be negligible compared to the all the other contributions. No clear relation is therefore expected between heat source pressure drops and NPV.

Last, it must be noted that such analysis highlights considerations, which might be useful when choosing an optimal working fluid for a specific case study. In fact, by looking at Fig.5 (a) and Fig.7, the mixture DME/-Pentane $(0.7 / 0.3)$ outperforms the other fluids both in terms of maximum NPV and COP found in the mapping, thereby suggesting the choice of such fluid as preferred option. However, the mixture Propane/n-Pentane (0.8/0.2) showed the weakest dependence on refrigerant pressure drops, thus offering an additional flexibility during the evaporator design process. It would therefore be up to the designer to evaluate and prioritize the different aspects. 


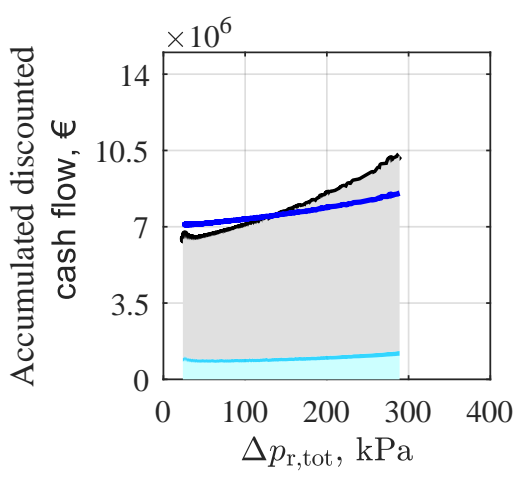

(a) Propane/Iso-Pentane $(0.5 / 0.5)$

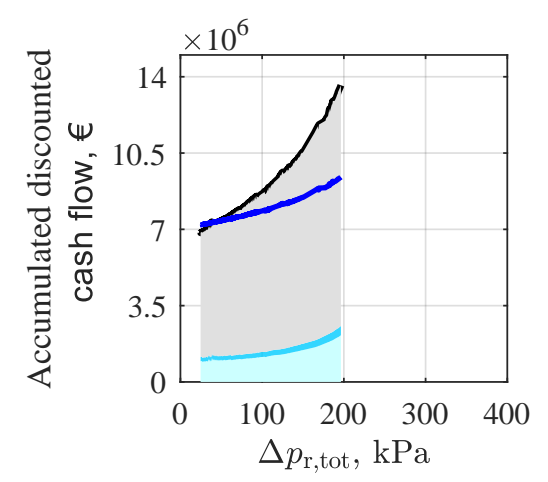

(d) Butane/Hexane (0.9/0.1)

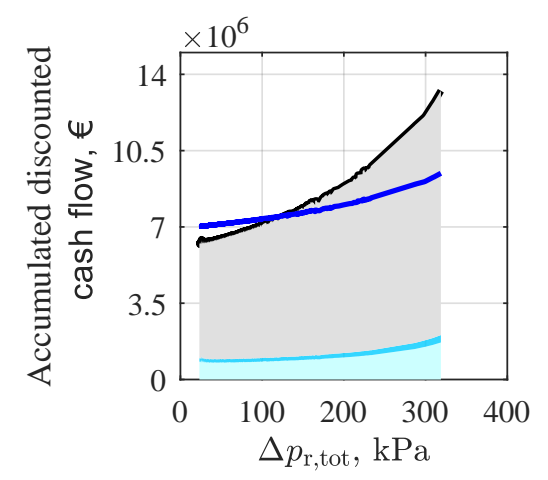

(g) DME/Iso-Pentane (0.5/0.5)

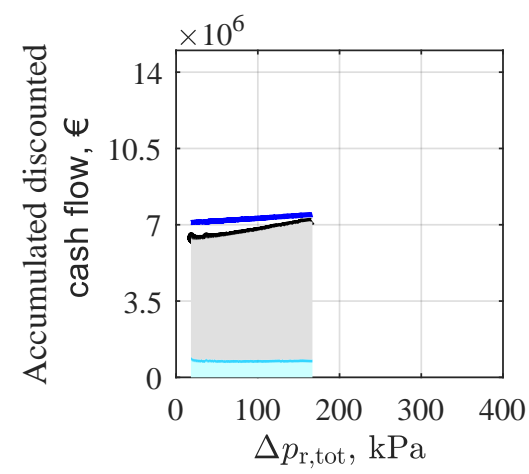

(b) Propane/n-Pentane (0.8/0.2)

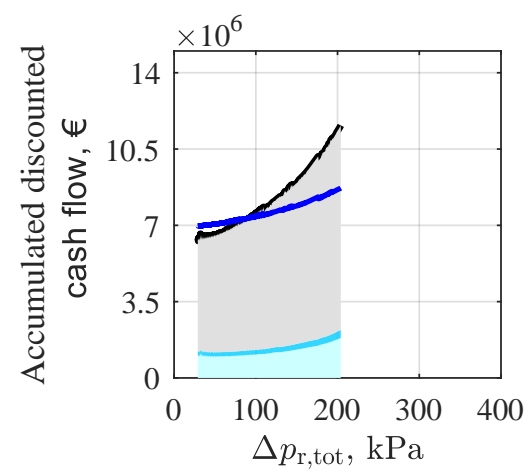

(e) DME/n-Pentane $(0.4 / 0.6)$

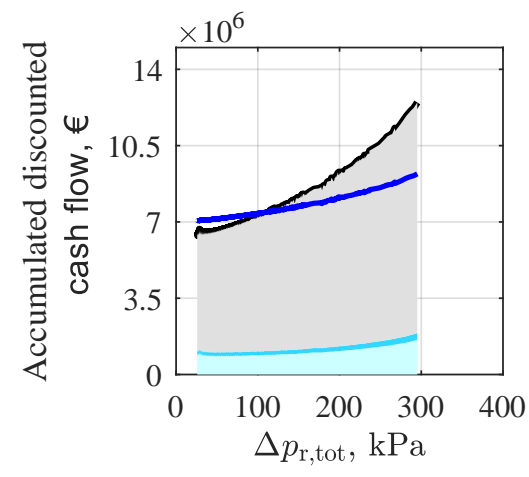

(h) Propylene/Iso-Pentane (0.4/0.6)

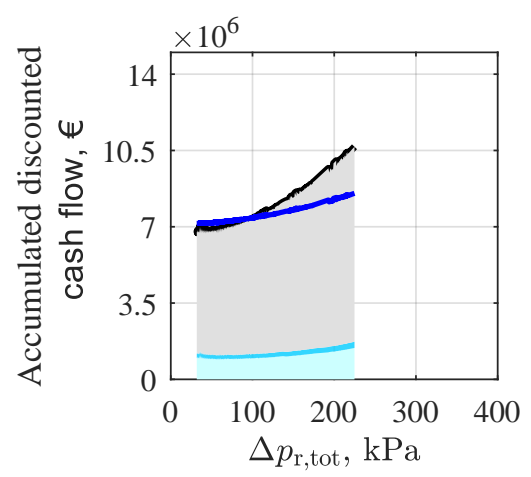

(c) Propane/n-Pentane (0.4/0.6)

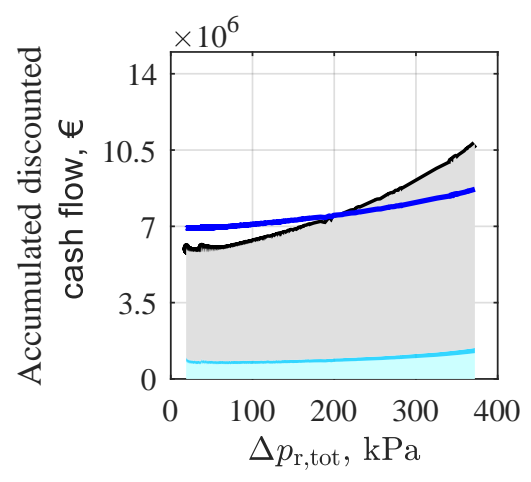

(f) DME/n-Pentane (0.7/0.3)

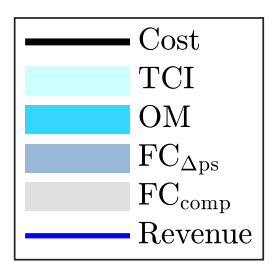

Figure 6: Breakdown of the contributions to the NPV, divided in cost and revenue. The colours indicate the different shares of the terms contributing to the cost stream 
- Pro-iPe $(0.5 / 0.5)$

- Pro-nPe(0.8/0.2)
- Pro-nPe(0.4/0.6)

- But-Hex(0.9/0.1)
- DME-nPe(0.4/0.6)

- DME-nPe(0.7/0.3)
- DME-iPe $(0.5 / 0.5)$

Propy-iPe $(0.4 / 0.6)$

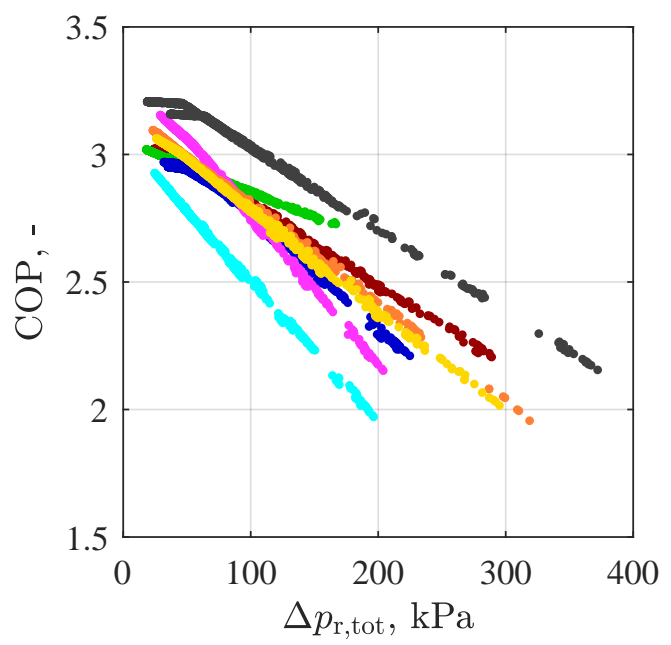

Figure 7: COP as function of the total refrigerant pressure drops for all the working fluids

- Pro-iPe $(0.5 / 0.5)$

- Pro-nPe(0.8/0.2)

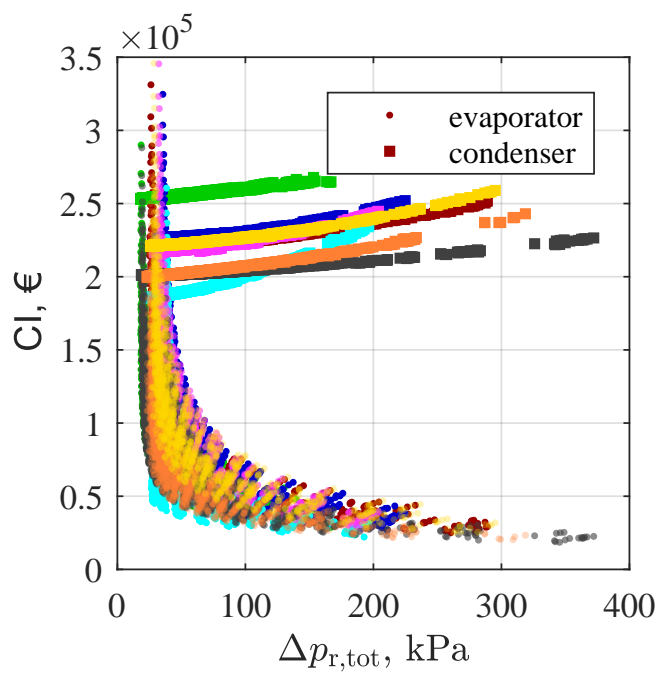

(a) heat exchangers
- Pro-nPe(0.4/0.6)

- But-Hex $(0.9 / 0.1)$
- DME-nPe(0.4/0.6) D DME-iPe(0.5/0.5)

- DME-nPe(0.7/0.3) - Propy-iPe(0.4/0.6)

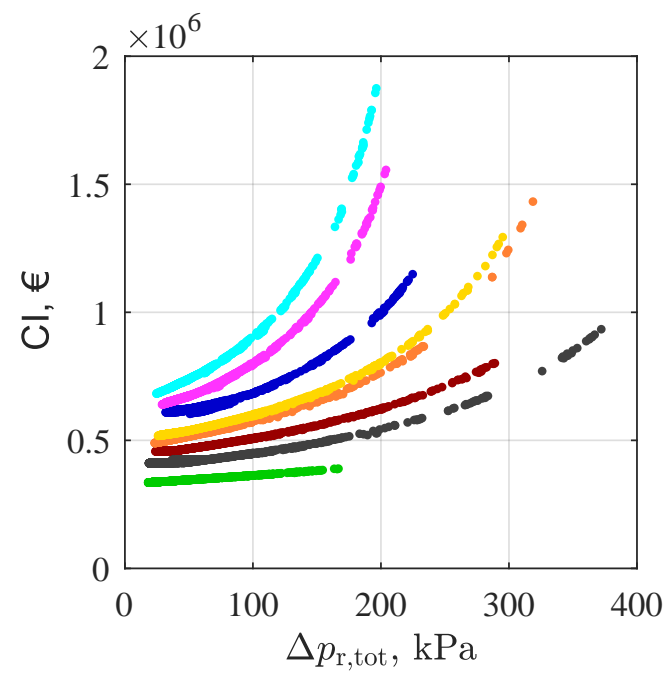

(b) compressor

Figure 8: Capital investment of the heat exchangers (a) and compressor (b), as function of the total refrigerant pressure drops for all the working fluids

\subsection{Correlation between NPV and non-dimensional parameters}

By exponentially correlating the design points by means of Eq.(19) to the chosen non-dimensional parameters, the $\mathrm{NPV}^{*}$ is found to be proportional to the combinations of dimensionless numbers reported by Eq.(20), indicated by $K$. 


$$
K=\theta^{* 0.045} \mathrm{Bd}^{0.051} \mathrm{We}_{m}^{-0.011} \rho^{*-0.066} \operatorname{Re}_{L O}^{0.009} \operatorname{Re}_{V}^{-0.12}
$$

Fig.9 reports the normalized net present value as function of $K$, for Propane/Iso-Pentane (0.5/0.5). The different colors represent the chevron angle of the PHE, namely $30^{\circ}, 45^{\circ}$ and $60^{\circ}$ corresponding to a value of non-dimensional inclination angle of $0.86,0.64$ and 0.43 , respectively. The trends for the other working fluids are not shown in the paper, but they are similar. The obtained design points are well correlated by $K$, and it is recommended to employ HEXs with $K=[0.4-0.6]$ at the evaporator inlet, in order to obtain solutions with NPV in the best $20 \%$. By increasing the value of $K$, the economic performance is negatively affected by the increase in heat transfer area, while for $K<0.4$ an increase of refrigerant pressure losses entails a steep decrease of NPV.

The use of a design guideline based on $\mathrm{K}$, which depends on six different parameters, might however lead to have redundant information on the boundary conditions and the fluids in the parameters. The problem was therefore simplified by relating the $\mathrm{NPV}^{*}$ to a selected number of non-dimensional parameters only. In order to do so, the results were assessed based on the coefficients and on additional considerations.

First, the dependence of the NPV on the liquid only Reynolds number $\mathrm{Re}_{\mathrm{LO}}$ is weak, since its exponent in Eq.(20) is two orders of magnitude lower than the vapour alone Reynolds number and one order of magnitude lower compared to the other parameters, thereby suggesting that a good fitting could be obtained by neglecting the influence of this non-dimensional number. Furthermore, it was decided to exclude the liquid to vapour density ratio $\rho^{*}$, since it contains information solely depending on the inlet densities and other dimensionless number, as the Reynolds numbers, the Weber number and the Bond number already contain the density characteristics of both vapour and liquid phases.

Lastly, by looking at the impact of the dimensionless inclination angle $\theta^{*}$ in Fig.9, the plot suggests that it is always optimal to minimize the chevron angle (hence enhancing the degree of turbulence of the fluid flow in the channels) if the PHE design is carried out in the optimal region or else for high value of $K$, i.e. designs with higher heat transfer area. On the contrary, with refrigerant dominant pressure losses $(K<0.4)$, it is slightly better to employ higher chevron angles for reaching less turbulent flow, thereby decreasing the pressure losses. It is therefore unnecessary to include the chevron angle into the design guideline, since it is possible to tune the other PHE design parameters in order to be in the optimal design region, where it is recommended to employ low values of $\beta$.

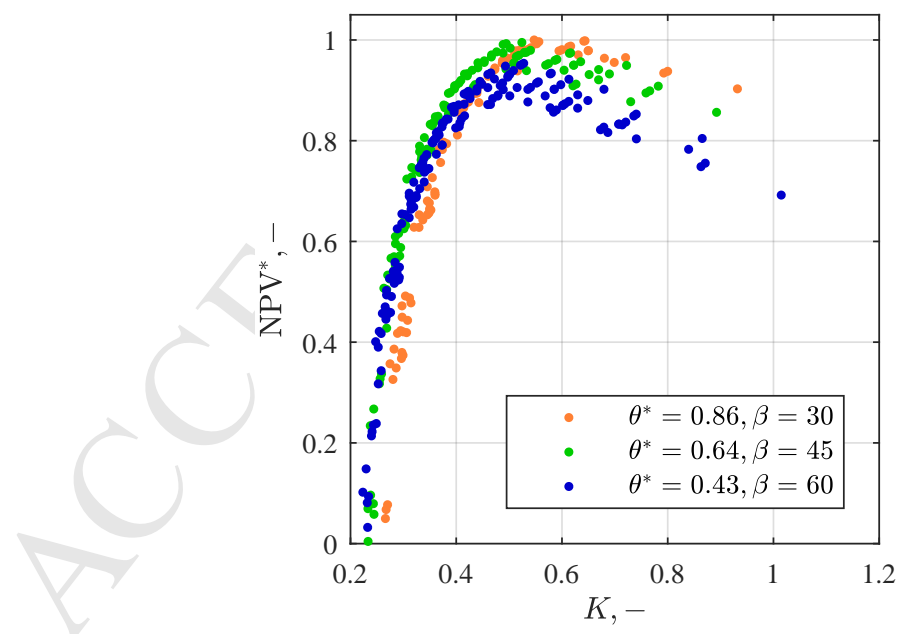

Figure 9: Normalized NPV as function of all the dimensionless parameters correlated exponentially for Propane/Iso-Pentane (0.5/0.5). The different colors represent the different chevron angles adopted

\subsection{Correlation between NPV and selected dimensionless numbers}

The results are presented as function of the three remaining dimensionless numbers, namely the Bond number $\mathrm{Bd}$, the Weber number $\mathrm{We}_{m}$ and the Reynolds number of the vapour flowing alone $\operatorname{Re}_{V}$. Table 6 shows the coefficients obtained by fitting the normalized net present values with different combinations of the three dimensionless parameters. 
Four different cases were assessed by combining the three parameters all at once and by considering combinations of only two of them. The aim was to find which correlation attained the best representation of NPV*, thereby being appropriate for deriving the design guideline. The values reported in the first row of the table (Case I), obtained by considering all the three non-dimensional numbers, suggest that there is not a predominant contribution of one of them, since the coefficients lie in a similar range.

Table 6: Coefficients obtained by fitting the $\mathrm{NPV}^{*}$ to different combinations of dimensionless parameters

\begin{tabular}{lcccc}
\hline Case & Parameters combination & $\mathrm{a}$ & $\mathrm{b}$ & $\mathrm{c}$ \\
\hline Case I & $\mathrm{Re}_{V}^{a} \cdot \mathrm{Bd}^{b} \cdot \mathrm{We}_{m}^{c}$ & 1.21 & -0.19 & -0.87 \\
Case II & $\mathrm{Bd}^{b} \cdot \mathrm{We}_{m}^{c}$ & 0.14 & -0.25 & \\
Case III & $\operatorname{Re}_{V}^{a} \cdot \mathrm{We}_{m}^{c}$ & 0.74 & - & -0.62 \\
Case IV & $\operatorname{Re}_{V}^{a} \cdot \mathrm{Bd}^{b}$ & -0.42 & 0.26 & - \\
\hline
\end{tabular}

Fig.10 shows the NPV* as a function of the different exponential combinations of dimensionless numbers, with the ordinate axis reporting the design points of all the working fluids. It can be observed that the normalized net present value presents a clear trend for all of the combinations. This is possibly related to the redundancy of information on geometry, fluid properties and boundary conditions contained in the three parameters.

By looking at the formulas reported in Table 4, $\mathrm{We}_{m}$ and $\mathrm{Re}_{V}$ are dependent on the hydraulic diameter $D_{h}$ and on the free flow area $A_{0}$, while the Bond number Bd solely depends on $D_{h}$. Any combinations of the parameters therefore contain all the information regarding the PHE geometry, i.e. the corrugation geometry, plate width and number of channel, with the exception of plate length (estimated by the PHE sizing for matching the thermal load and thus not needed to be included in the guideline) and chevron angle, excluded from the guideline.

Moreover, by looking at the fluid properties of the three non-dimensional numbers, it can be seen that surface tension $\sigma$ and the liquid and vapour phase densities $\rho_{L}$ and $\rho_{V}$ are contained in any of considered combinations, together with the inlet vapour quality $x$ and mass flow $\dot{m}_{r}$.

In order to choose which combination of parameters to consider for the final design guideline, the position of the optimal values of the different coefficients was compared for the different working fluids. The aim was to understand which design guideline resulted in a recommendation which was narrower to describe the optimal NPV* for all the working fluids.

Table 7 reports the minimum, maximum and mean values of the different cases for the best solutions, which were selected as $\mathrm{NPV}^{*}$ deviating at most $5 \%$ from each best solution. The results are reported for all the working fluids, as well as the overall maximum, minimum and mean value. The deviation (last row) was estimated by considering how far the minimum and maximum value were from the overall mean.

The results suggest that the best agreement between the different mixtures is obtained by the combination of $\operatorname{Re}_{V}$ and $\mathrm{Bd}$, whose deviations are $-34 \%$ and $48 \%$ for the minimum and maximum value, respectively. The interval covered by Butane/Hexane(0.9/0.1) is shifted towards the left compared to the other working fluids. 
- Pro-iPe $(0.5 / 0.5)$

- Pro-nPe(0.8/0.2)
- Pro-nPe(0.4/0.6) - But-Hex(0.9/0.1)
- DME-nPe(0.4/0.6)

- DME-nPe(0.7/0.3)
DME-iPe $(0.5 / 0.5)$

Propy-iPe $(0.4 / 0.6)$

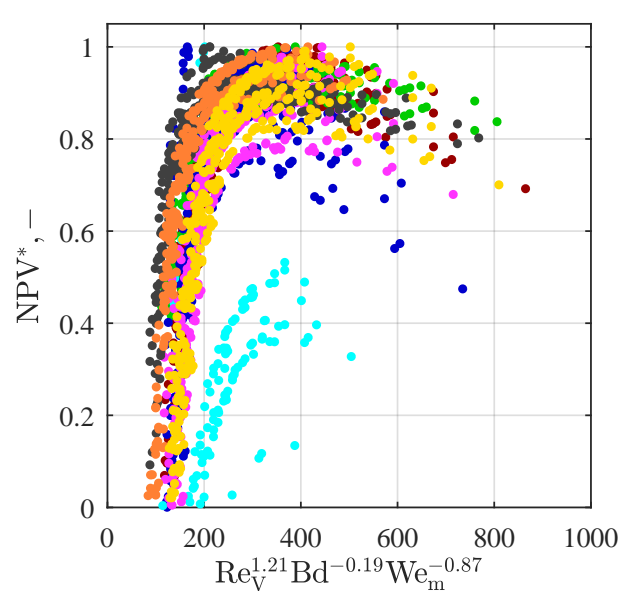

(a) Case I

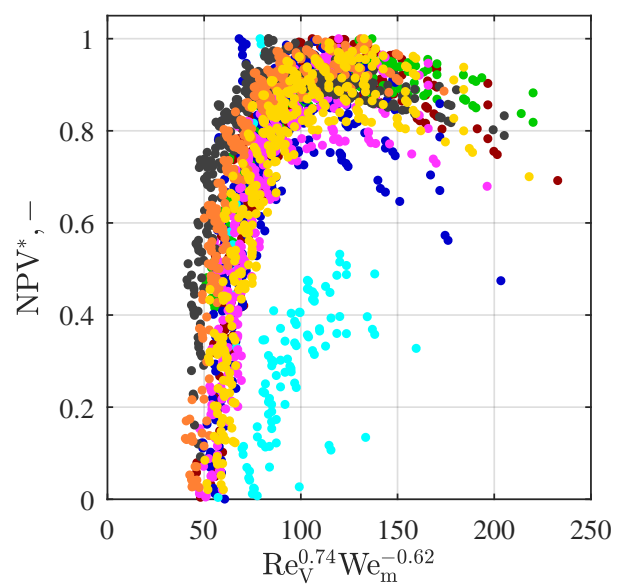

(c) Case III

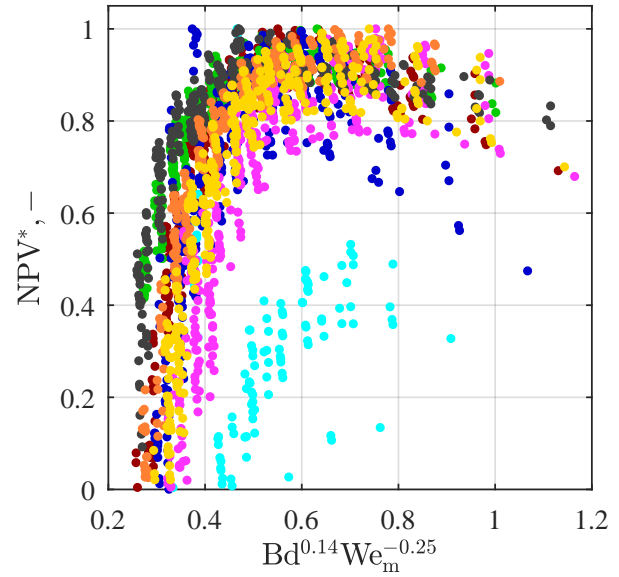

(b) Case II

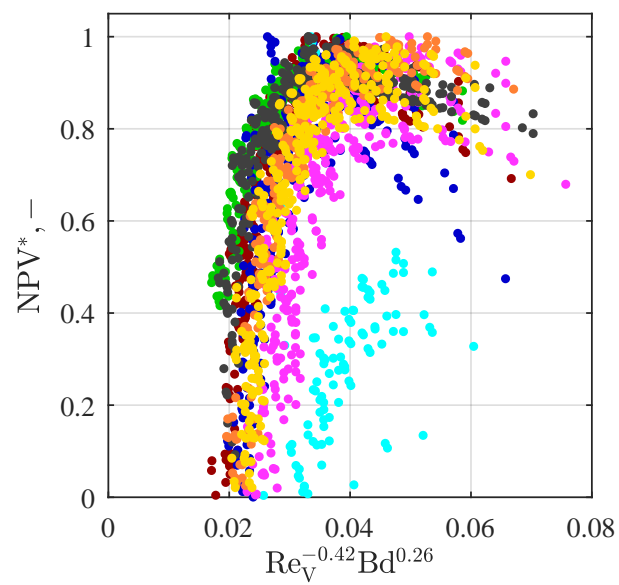

(d) Case IV

Figure 10: Normalized NPV as function of different combinations of non-dimensional numbers for all the working fluids reported in Table 6; (a)Case I; (b)Case II; (c)Case III; (d)Case IV 
Table 7: Minimum, maximum and average values of different combinations of dimensionless numbers for the best results $\left(5 \% \mathrm{NPV}^{*}\right)$, for each working fluid and overall

\begin{tabular}{|c|c|c|c|c|c|c|c|c|c|c|c|c|}
\hline \multirow[b]{2}{*}{ Working fluid } & \multicolumn{3}{|c|}{$\begin{array}{c}\text { Case I } \\
\operatorname{Re}_{V}^{1.21} \cdot \mathrm{Bd}^{-0.19} \cdot \mathrm{We}_{m}^{-0.87}\end{array}$} & \multicolumn{3}{|c|}{$\begin{array}{c}\text { Case II } \\
\mathrm{Bd}^{0.14} \cdot \mathrm{We}_{m}^{-0.25}\end{array}$} & \multicolumn{3}{|c|}{$\begin{array}{c}\text { Case III } \\
\mathrm{Re}_{V}^{0.74} \cdot \mathrm{We}_{m}^{-0.62}\end{array}$} & \multicolumn{3}{|c|}{$\begin{array}{c}\text { Case IV } \\
\operatorname{Re}_{V}^{-0.42} \cdot \mathrm{Bd}^{0.26}\end{array}$} \\
\hline & $\min$ & $\max$ & mean & $\min$ & $\max$ & mean & $\min$ & $\max$ & mean & $\min$ & $\max$ & mean \\
\hline Propane/Iso-Pentane $(0.5 / 0.5)$ & 2110 & 3310 & 2620 & 0.48 & 0.75 & 0.59 & 91.4 & 152 & 118 & 0.030 & 0.047 & 0.038 \\
\hline Propane/n-Pentane $(0.8 / 0.2)$ & 2240 & 3800 & 2900 & 0.48 & 0.77 & 0.60 & 104 & 166 & 128 & 0.031 & 0.046 & 0.037 \\
\hline Propane/n-Pentane $(0.4 / 0.6)$ & 1420 & 2780 & 2130 & 0.37 & 0.70 & 0.54 & 68 & 129 & 99 & 0.026 & 0.045 & 0.036 \\
\hline Butane/Hexane $(0.9 / 0.1)$ & 1560 & 1570 & 1560 & 0.47 & 0.47 & 0.47 & 78.9 & 80.9 & 79.8 & 0.034 & 0.034 & 0.034 \\
\hline DME/n-Pentane $(0.4 / 0.6)$ & 2150 & 2800 & 2380 & 0.65 & 0.86 & 0.72 & 103 & 144 & 118 & 0.044 & 0.058 & 0.049 \\
\hline DME/n-Pentane $(0.7 / 0.3)$ & 1640 & 2430 & 1930 & 0.46 & 0.67 & 0.53 & 81.3 & 121 & 96 & 0.032 & 0.045 & 0.037 \\
\hline DME/Iso-Pentane $(0.5 / 0.5)$ & 1810 & 2920 & 2190 & 0.55 & 0.88 & 0.66 & 88 & 151 & 111 & 0.038 & 0.059 & 0.046 \\
\hline Propylene/Iso-Pentane $(0.4 / 0.6)$ & 2100 & 3330 & 2670 & 0.52 & 0.84 & 0.67 & 93 & 160 & 124 & 0.034 & 0.054 & 0.043 \\
\hline Overall & 1420 & 3800 & 2300 & 0.37 & 0.88 & 0.60 & 68 & 166 & 109 & 0.026 & 0.059 & 0.040 \\
\hline Deviation in $\%$ & $-38 \%$ & $65 \%$ & & $-38 \%$ & $46 \%$ & & $-38 \%$ & $-52 \%$ & & $-34 \%$ & $-48 \%$ & \\
\hline
\end{tabular}

Fig.11 shows the positive solutions of NPV for all the working fluids as function of the obtained parameter ${ }_{405} \mathrm{Re}_{\mathrm{V}}{ }^{-0.42} \mathrm{Bd}^{0.26}$. The red line represents the mean value, equal to 0.040 , while the dotted black lines represent the minimum (0.026) and maximum value (0.059). The plots show that all the fluids, except Butane/Hexane (0.91/0.1), present a good agreement with the obtained guideline: the optimal NPV points are all included in the interval [0.0400.059], with the peak lying around 0.040 for almost all the fluids. DME/n-Pentane (0.4/0.6) and DME/Iso-Pentane $(0.5 / 0.5)$ have the maximum slightly shifted towards 0.050 . They perform however with NPV* very close to the opti410 mum for 0.040 (equal or above $80 \%$ of the optimal value). Propane/n-Pentane(0.4/0.6) shows solutions with NPV* going down to $-30 \%$ for the optimal value for 0.040 . The worst performing points are probably related to higher values of chevron angle (see Fig.9), thus optimal designs can be achieved as well with the proposed guideline. In agreement with the numbers reported in Table 7, Butane/Hexane (0.91/0.1) is slightly shifted towards the left compared to the other fluids, i.e. with optimal points in the interval [0.026-0.040]. Nonetheless it has been decided not

415 to shift the design interval towards values optimal for this fluid, since it was shown that this mixture performed with generally lower NPV in the mapping compared to all the other fluids (see Fig.6).

After the assessment of the results from Table 7 and Fig.11, it was decided to propose the guideline presented by Eq.21 as design recommendation.

$$
\operatorname{Re}_{V}^{-0.42} \mathrm{Bd}^{0.26} \approx 0.040
$$

If a higher value is obtained, the PHE design is expected to lead to higher equipment investment (related to the heat 420 transfer area), while a lower value will lead to high refrigerant pressure drop, resulting in a steep decrease of both COP and NPV. 


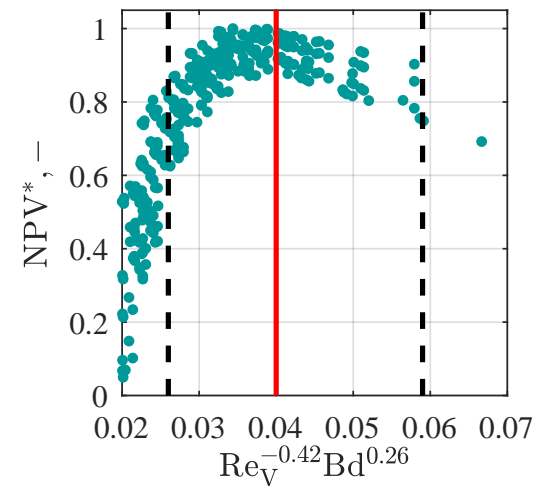

(a) Propane/Iso-Pentane (0.5/0.5)

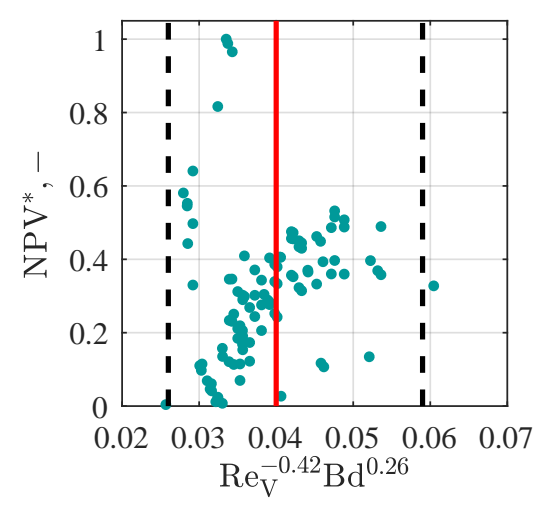

(d) Butane/Hexane (0.9/0.1)

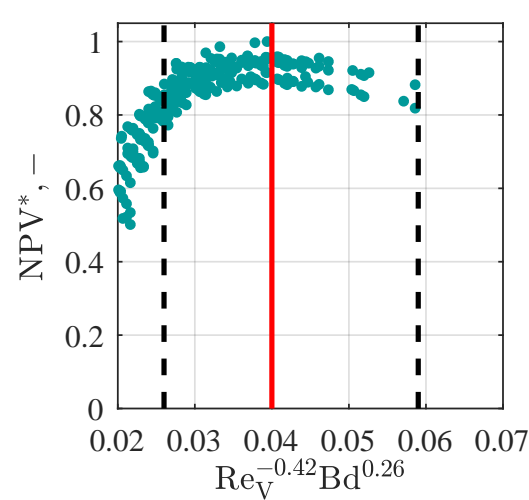

(b) Propane/n-Pentane (0.8/0.2)

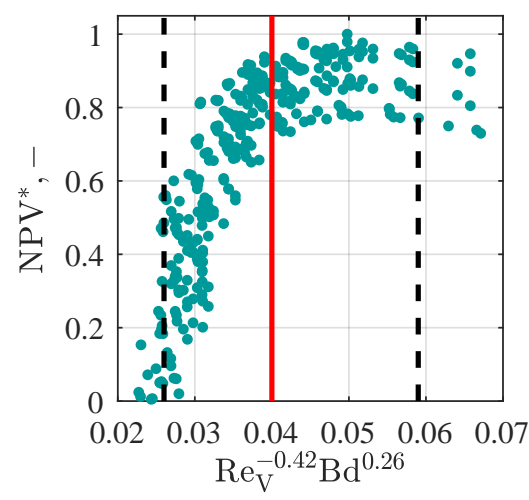

(e) DME/n-Pentane (0.4/0.6)

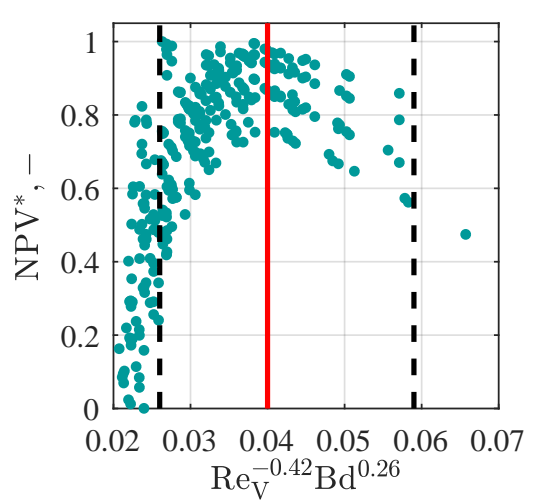

(c) Propane/n-Pentane (0.4/0.6)

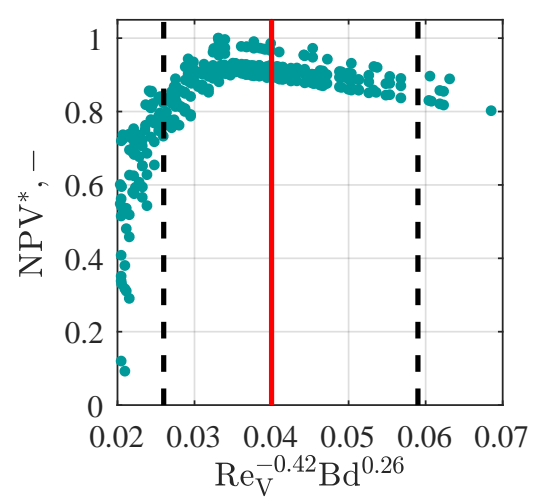

(f) DME/n-Pentane (0.7/0.3)

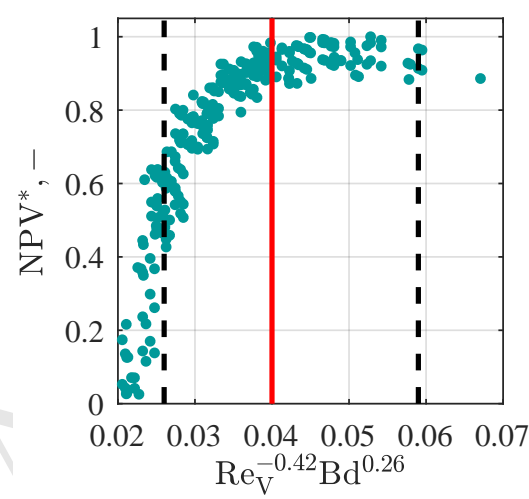

(g) DME/Iso-Pentane (0.5/0.5)

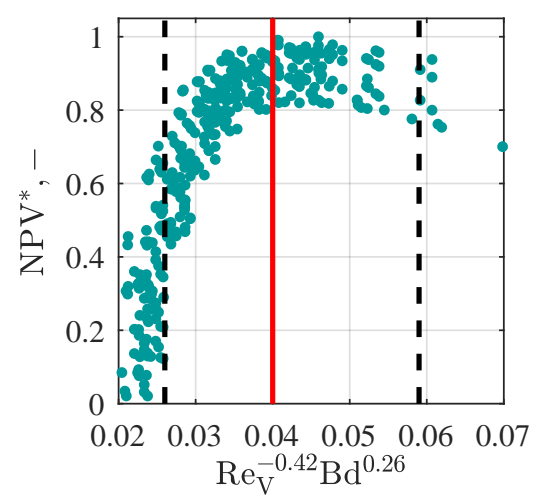

(h) Propylene/Iso-Pentane (0.4/0.6)

Figure 11: Normalized NPV as function of $\operatorname{Re}_{\mathrm{V}}{ }^{-0.42} \mathrm{Bd}^{0.26}$ for all the working fluids. The red line represents the mean value $\mathrm{Re}_{V}^{-0.42} \mathrm{Bd}^{0.26}=0.04$, while the dotted lines represent max and min, 0.059 and 0.026 respectively. 


\section{Discussion}

Section 4.1 presents the discussion of an application of the derived guideline, Section 4.2 reports the results of the uncertainty analysis while Section 4.3 briefly comments on the deviation of the obtained guideline if an alternative prediction method is used for the refrigerant pressure drop estimation, which resulted to have the largest impact on the heat pump economic performance. Section 4.4 highlights the limitation of the study and potential future work.

\subsection{Application of the derived design recommendation}

The case of the first working fluid mixture was considered, namely Propane/Iso-Pentane (0.5/0.5). The design, based on the derived guideline consists of the following steps:

1. Fix the boundary conditions of the thermodynamic cycle and estimate the inlet condition at the evaporator (quality, mass flow, evaporation pressure).

2. Calculate the following fluid properties at the inlet condition: $\rho_{L}, \rho_{V}, \sigma, \mu_{V}$.

3. Choose a value for the chevron angle $\beta$. It is recommended to employ low values (e.g. $30-35^{\circ}$ ), if the design parameter is not constrained.

4. Decide which design parameters are fixed by external boundaries (fixed plate size and/or numbers and/or corrugation geometry).

5. Tune the remaining free design parameters in order to obtain $\operatorname{Re}_{V}^{-0.42} \mathrm{Bd}^{0.26} \approx 0.040$. Calculate the required plate length by using the evaporator heat flow rate, fixed by the cycle.

Table 8 shows different combinations of geometrical parameters, each line corresponding to a different PHE design.

Some geometrical parameters were fixed a priori, while other were calculated by means of the design guideline using the methodology presented above. The goal of fixing and releasing different geometrical parameters was to show the different possible scenarios of a designer, which might be constrained in some of the design variables. The plate length was estimated by the sizing model, matching the case study thermal load.

In the first three rows of the table, the corrugation geometry, namely pitch $\Lambda$ and height $b$, were fixed together with the corrugation angle. The number of channels $N_{\mathrm{ch}}$ and plate width $W$ were found in order to obtain values of $\operatorname{Re}_{V}^{-0.42} \mathrm{Bd}^{0.26}$ equal to 0.040 . It can be noticed that by respecting the proposed design guideline, the NPV deviates maximum $-4.4 \%$ from the best value of the parametric analysis. The COP in the third design point is slightly lower due the the higher pressure drops of the refrigerant.

The forth and fifth rows of Table 8 report two PHE design which were obtained by fixing the plate width and the number of plates, as well as the chevron angle. The corrugation geometry was found in order to match the design guideline and it was found that also in this case the two solutions deviate of only $-1.9 \%$ and $-1.5 \%$ from the best NPV, thereby lying in an optimal region for the PHE design. It can be noticed that all the five solutions proposed have the same magnitude of refrigerant pressure drops, ranging from $30 \mathrm{kPa}$ to $35 \mathrm{kPa}$. This is the same range shown in Fig.6(a) for the same working fluid.

Table 8: Some examples of PHE design points for the mixture Propane/Iso-Pentane (0.5/0.5)

\begin{tabular}{|c|c|c|c|c|c|c|c|c|c|c|c|c|}
\hline Design & $\begin{array}{c}W \\
{[\mathrm{~m}]}\end{array}$ & $\begin{array}{l}N_{\mathrm{ch}} \\
{[-]}\end{array}$ & $\begin{array}{l}\beta \\
{\left[{ }^{\circ}\right]}\end{array}$ & $\begin{array}{c}b \\
{[\mathrm{~m}]}\end{array}$ & $\begin{array}{c}\Lambda \\
{[\mathrm{m}]}\end{array}$ & $\begin{array}{l}L_{\mathrm{HT}} \\
{[\mathrm{m}]}\end{array}$ & $\begin{array}{l}A_{\mathrm{ht}} \\
{\left[\mathrm{m}^{2}\right]}\end{array}$ & $\begin{array}{c}\Delta p_{\mathrm{r}-\mathrm{tot}} \\
{[\mathrm{kPa}]}\end{array}$ & $\begin{array}{l}\text { NPV } \\
{[€]}\end{array}$ & $\begin{array}{c}\Delta \mathrm{NPV} \\
{[\%]}\end{array}$ & $\begin{array}{l}\text { COP } \\
{[-]}\end{array}$ & $\begin{array}{c}\mathrm{Re}_{V}^{-0.42} \mathrm{Bd}^{0.26} \\
{[-]}\end{array}$ \\
\hline & \multicolumn{2}{|c|}{ Free variables } & \multicolumn{3}{|c|}{ Fixed geometry } & & & & & & & \\
\hline I & 0.20 & 188 & 45 & 0.005 & 0.007 & 0.66 & 92.0 & 31.0 & 696,960 & -3.6 & 3.02 & 0.040 \\
\hline II & 0.19 & 196 & 35 & 0.005 & 0.007 & 0.57 & 80.1 & 31.3 & 711,620 & -1.5 & 3.02 & 0.040 \\
\hline \multirow[t]{2}{*}{ III } & 0.44 & 59 & 35 & 0.007 & 0.007 & 0.65 & 80.7 & 36.0 & 690,990 & -4.4 & 3.01 & 0.040 \\
\hline & \multicolumn{3}{|c|}{ Fixed geometry } & \multicolumn{2}{|c|}{ Free variables } & & & & & & & \\
\hline IV & 0.20 & 100 & 35 & 0.009 & 0.008 & 0.77 & 82.1 & 32.6 & 708,580 & -1.9 & 3.02 & 0.040 \\
\hline V & 0.18 & 150 & 35 & 0.007 & 0.006 & 0.54 & 79.8 & 31.0 & 712,180 & -1.5 & 3.02 & 0.040 \\
\hline
\end{tabular}




\subsection{Uncertainty analysis}

The uncertainty analysis of the values of heat transfer coefficients and pressure drops was carried out for the design I reported in Table 8 for Propane/Iso-Pentane (0.5/0.5), performing with a NPV $-3.6 \%$ lower than the best solution found in the mapping. The mean values, standard deviation and $95 \%$ coverage interval are reported in Table 9 . The input uncertainties assigned to the heat transfer and pressure drop correlations resulted in a standard deviation of 10.6 $\%$ and $5.0 \%$ for heat transfer area and refrigerant pressure drops, respectively. However, the overall impact on the heat pump NPV resulted to be only equal to a $1.8 \%$ standard deviation. This was also translated to $95 \%$ of all the solutions deviating maximum $3.5 \%$ from the mean. Moreover, it can be observed that the PHE design I obtained in Table 8 deviated only $0.3 \%$ compared to the mean value estimated performing 500 simulations from the uncertainty input space. The heat source pressure drop is not reported, since the results showed a negligible impact on the NPV.

Table 9: MC uncertainty analysis results for PHE design I for Propane/Iso-Pentane (0.5/0.5) performed with a sample population of 500 elements

\begin{tabular}{lccc}
\hline & $A_{\mathrm{ht}}$ & $\Delta p_{\mathrm{r}, \text { tot }}$ & $\mathrm{NPV}$ \\
\hline Mean value & $93.2 \mathrm{~m}^{2}$ & $33.2 \mathrm{kPa}$ & $694,780 €$ \\
Absolute standard deviation & $9.9 \mathrm{~m}^{2}$ & $1.7 \mathrm{kPa}$ & $12,370 €$ \\
Percentage standard deviation & $10.6 \%$ & $5.0 \%$ & $1.8 \%$ \\
$95 \%$ coverage interval & $20.7 \%$ & $9.8 \%$ & $3.5 \%$ \\
\hline & & & \\
Design I & $92.0 \mathrm{~m}^{2}$ & $31.0 \mathrm{kPa}$ & $696,960 €$ \\
Deviation from the mean & $-1.3 \%$ & $-6.8 \%$ & $+0.3 \%$ \\
\hline
\end{tabular}

By using the same fitting coefficients obtained using the previous data set, i.e. -0.42 and 0.26 for $\operatorname{Re}_{V}$ and $\mathrm{Bd}$ respectively, the mean value was calculated for the best results, namely PHE designs based on the best $5 \%$ NPV. A good agreement was obtained between the two different data sets, since the mean value of the guideline $\operatorname{Re}_{V}^{-0.42} \mathrm{Bd}^{0.26}$ was found equal to 0.044 , thereby being $+9.5 \%$ higher than the base case. 


\subsection{Limitations and future work}

The methodology presented in this work is based on a number of boundary conditions and assumptions. First and foremost, the methodology is based on numerical calculations and has not been documented experimentally. The study has only been applied to a limited number of cases. The work should be seen as a suggestion and exemplification of a method, rather than a complete guideline. The methodology was indeed derived for eight different working fluids integrated in the same heat pump, with fixed heat source temperature glide of $25^{\circ} \mathrm{C}$. The influence of having different glides along the evaporator might be investigated as part of future work.

The economic analysis showed that the refrigerant total pressure drops have a major impact on the NPV of the heat pump. In order to estimate the NPV, a number of economic boundaries were assumed, and the price of electricity and natural gas were based on the data available for the Danish energy sector. Furthermore, the case study was based on a waste heat recovery application, where the heat source comes at zero cost. The COP decrease, entailing a compressor running cost, could be partially balanced by a reduced utilization of the heat source. The economic boundaries are therefore dependent on the specific case study, and the application of the presented methodology should be adapted to the specific boundary conditions.

Last, it is worth it mentioning two limitations imposed by the PHE sizing model. Flow maldistributions are not taken into consideration, neither along the plate width nor among the different HEX channels. This aspect might lead to different results concerning some design variables, e.g. plate length-to-width ratio, since it does not take into account that the flow might not be perfectly counter-current if low values of such ratio are employed. In order to avoid unrealistic results, a minimum ratio was assumed in the present analysis.

\section{Conclusions}

This paper presented a methodology to derive design guidelines for plate heat exchangers. The methodology was demonstrated by applying it to a case study of plate heat exchanger evaporators in heat pumps using zeotropic mixtures. The basis for the derivation was a numerical model used for simultaneous sizing of the thermodynamic cycle and of the heat exchanger, with heat transfer area and pressure drops being considered for both the calculation of the cycle COP and NPV.

The analysis showed that there is an economic trade-off between heat transfer area and refrigerant pressure drop, with the latter having a larger impact on the results. Higher refrigerant pressure drops resulted in a COP degradation, subsequent increase of the compressor running costs, as well as higher investment required for the compressor. Different working fluids presented different sensitivity to pressure drops, thus the trade-off could not be uniquely defined in terms of a maximum allowable pressure drop.

The results were therefore assessed with the aim of deriving a general design guideline, applicable for all the fluids. Different non-dimensional parameters were correlated to the normalized net present value, and it was shown that $\mathrm{Re}_{V}, \mathrm{Bd}$ and $\mathrm{We}_{m}$ are the parameters mostly influencing the results. Moreover, an optimal value was identified for the dimensionless factor $\mathrm{Re}_{V}^{-0.42} \mathrm{Bd}^{0.26}$ for the best solutions in terms of NPV, deviating no more than $5 \%$ from the highest NPV. It was shown that for most of the mixtures values above $80 \%$ of the best NPV were found for $\operatorname{Re}_{V}^{-0.42} \mathrm{Bd}^{0.26} \approx 0.040$

Butane/Hexane(0.9/0.1) presented non-favourable design points, with an optimal region shifted towards the left of the obtained guideline. Moreover, Propane/n-Pentane at (0.4/0.6) reported values of NPV above $70 \%$ of the best solution for the suggested guideline, performing slightly worse than the other working fluids for some of the designs. This was related to the effect of the chevron angle, and it was therefore recommended to employ low values of $\beta$ in the optimal region.

The design steps, based on applying the aforementioned guideline, were summarized and applied to the case of for the Propane/Iso-Pentane (0.5/0.5). It was illustrated that different configurations respecting $\operatorname{Re}_{V}^{-0.42} \mathrm{Bd}^{0.26} \approx 0.040$ yielded close to optimal NPVs. These were obtaining by tuning differently plate corrugation geometry, size and number of plates.

Moreover, an uncertainty analysis of the heat transfer coefficients and pressure drops estimated by experimental correlations was carried out for one of the optimal designs of Propane/Iso-Pentane (0.5/0.5), using the MC method on a population sample of 500 elements obtained using LHS. The NPV mean value was found to be $0.3 \%$ higher than the design point, with a standard deviation of $1.8 \%$ 
The presented methodology offers the possibility of deriving guidelines for different applications, where HEXs are integrated in a thermodynamic cycle and different working fluids are compared, avoiding computationally expensive combined cycle and component optimization to obtain feasible designs.

\section{Acknowledgments}

The research work was conducted within the frame of the THERMCYC project (Advanced thermodynamic cycles utilizing low temperature heat sources) funded by Innovations Fund Denmark: The Danish Council for Strategic Research in Sustainable Energy and Environment. The support is gratefully acknowledged.

$\dot{Q} \quad$ heat load $[W]$

$\dot{W} \quad$ work $[\mathrm{W}]$

$\dot{m} \quad$ mass flow $[\mathrm{kg} / \mathrm{s}]$

$b \quad$ corrugation height [m]

${ }_{560} c_{\text {el }}$

$f \quad$ Fanning friction factor [-]

$g$ gravitational acceleration $\left[\mathrm{m} / \mathrm{s}^{2}\right]$

$h \quad$ heat transfer coefficient $\left[\mathrm{W} /\left(\mathrm{m}^{2} \mathrm{~K}\right)\right]$

$n \quad$ number of control volumes [-]

${ }_{565} \quad p \quad$ pressure $[\mathrm{Pa}]$

$t \quad$ plate thickness [m]

$x \quad$ vapour quality [-]

Bd Bond number [-]

COP coefficient of performance [-]
570 CRF capital recovery factor[1/a]

FC fuel cost $[€ / a]$

NPV net present value [€]

OMC operation and maintenance cost $[€]$

PEC purchased equipment $\operatorname{cost}[€]$

575 Re Reynolds number [-]

TCI total capital investment[€]

We Weber number [-]

\section{Abbreviations and acronyms}

CI capital investment

580 CV control volume

HEX heat exchanger

LHS latin hypercube sampling

MC Monte Carlo

PHE plate heat exchanger

\section{${ }_{585}$ Greek letters}

$\beta \quad$ chevron angle $\left[{ }^{\circ}\right]$

$\Delta \quad$ difference [-]

$\eta \quad$ efficiency [-]

$\Lambda \quad$ corrugation thickness [m]

${ }_{590} \mu \quad$ viscosity $[\mathrm{Pa} \cdot \mathrm{s}]$

$\Phi \quad$ enlargement factor [-]

$\rho \quad$ density $\left[\mathrm{kg} / \mathrm{m}^{3}\right]$

$\sigma \quad$ surface tension $[\mathrm{N} / \mathrm{m}]$

$\tau \quad$ time $[\mathrm{hr}]$

$\theta \quad$ inclination angle $(90-\beta)\left[^{\circ}\right]$

\section{Superscripts}




$\begin{array}{lll} & & \text { per unit area } \\ * & \text { normalized } \\ \text { i } & \text { control volum } \\ 600 & \mathrm{j} & \text { solver iteratio } \\ \text { Subscripts } \\ \text { acc } & \text { acceleration } \\ \text { C } & \text { convective } \\ \text { comp } & \text { compressor } \\ 605 & \text { ev } & \text { evaporation } \\ \text { fr } & \text { friction } \\ \text { gr } & \text { gravity } \\ \text { hp } & \text { heat pump } \\ \text { ht, HT } & \text { heat transfer } \\ \text { id } & \text { ideal } \\ \text { id } & \text { mixture } \\ \text { in } & \text { inlet } \\ \text { is } & \text { isentropic }\end{array}$

630

\section{References}

[1] B. Zühlsdorf, F. Bühler, R. Mancini, S. Cignitti, B. Elmegaard, High Temperature Heat Pump Integration using Zeotropic Working Fluids for Spray Drying Facilities, in: Proceedings of the 12th IEA Heat pump conference, Rotterdam, 2017.

[2] B. Zühlsdorf, J. Kjaer Jensen, S. Cignitti, C. Madsen, B. Elmegaard, Analysis of temperature glide matching of heat pumps with zeotropic working fluid mixtures for different temperature glides, Energydoi: $10.1016 / \mathrm{j}$. energy .2018 .04 .048 .

635 [3] B. Zühlsdorf, W. Meesenburg, T. Ommen, J. Thorsen, W. Brix Markussen, B. Elmegaard, Improving the performance of booster heat pumps using zeotropic mixtures, Energy, in pressdoi:https://doi.org/10.1016/j .energy .2018.04.137.

[4] J. G. Collier, J. Thome, Convective boiling and condensation, 1994. arXiv:arXiv:1011.1669v3, doi:10.1016/0923-0467 (95) 80021-2.

[5] R. Radermacher, Y. Hwang, Heat Transfer of Refrigerant Mixturers, in: Vapor Compression Heat Pumps with Refrigerant Mixtures, CRC Press 2005, 2005, Ch. 8, pp. 237-278. doi : doi:10.1201/9781420037579.ch8.

[6] H. Ross, R. Radermacher, M. di Marzo, D. Didion, Horizontal flow boiling of pure and mixed refrigerants, International Journal of Heat and Mass Transfer 30 (5) (1987) 979-992. doi:10.1016/0017-9310(87) 90016-0.

[7] P. Wattelet, C. Chato, A. L. Souza, B. Christofferson, Initial Evaporative Comparison of R-22 with Alternative Refrigerants R-134a and R-32/R-125, Tech. rep., University of Illinois (1993).

[8] D. Jung, M. McLinden, R. Radermacher, D. Didion, A study of flow boiling heat transfer with refrigerant mixtures, International Journal of Heat and Mass Transfer 32 (9) (1989a) 1751-1764. doi:10.1016/0017-9310 (89) 90057-4.

[9] D. S. Jung, M. McLinden, R. Radermacher, D. Didion, Horizontal flow boiling heat transfer experiments with a mixture of R22/R114, International Journal of Heat and Mass Transfer 32 (1) (1989b) 131-145. doi:10.1016/0017-9310 (89) 90097-5.

[10] K. Torikoshi, T. Ebisu, Heat transfer and pressure drop of R134a R32 and a mixture of R32 R134a, ASHRAE Transactions 99 (2) (1993) 90-93.

[11] R. K. Shah, D. P. Sekulic, Fundamentals of Heat Exchanger Design, 2002. doi:10.1002/9780470172605.

[12] VDI-Gesellschaft, VDI Heat Atlas, Vol. 1, 2015. doi:10.1007/978-3-540-77877-6.

[13] J. a.W. Gut, J. M. Pinto, Optimal configuration design for plate heat exchangers, International Journal of Heat and Mass Transfer 47 (22) (2004) 4833-4848. doi:10.1016/j.ijheatmasstransfer.2004.06.002.

655 [14] F. Jegede, G. Polley, Optimum heat exchanger design, Chemical Engineering Research and Design 70 (A2) (1992) 133-141.

[15] A. Unuvar, S. Kargici, An approach for the optimum design of heat exchangers, International Journal of Energy Research 28 (15) (2004) 1379-1392. doi:10.1002/er.1080. 
[16] K. Muralikrishna, U. Shenoy, Heat Exchanger Design Targets for Minimum Area and Cost, Chemical Engineering Research and Design 78 (2) (2000) 161-167. doi:10.1205/026387600527185.

[17] E. Jarzebeski, E. Wardas-Koziel, Dimensioning plate heat exchangers giving minimum annual operating costs, Chemical Engineering Research and Design 63 (4) (1985) 211-218.

[18] L. Wang, B. Sundén, Optimal design of plate heat exchangers with and without pressure drop specifications, Applied Thermal Engineering 23 (3) (2003) 295-311. doi:10.1016/S1359-4311(02)00195-3.

[19] S. Karellas, A. Schuster, A.-D. Leontaritis, Influence of supercritical ORC parameters on plate heat exchanger design, Applied Thermal Engineering 33-34 (2012) 70-76. doi:10.1016/j.applthermaleng.2011.09.013.

[20] N. Rohmah, G. Pikra, A. J. Purwanto, R. I. Pramana, The Effect of Plate Spacing in Plate Heat Exchanger Design as a Condenser in Organic Rankine cycle for Low Temperature Heat Source, Energy Procedia 68 (2015) 87-96. doi :10.1016/j.egypro.2015.03.236.

[21] D. Walraven, B. Laenen, W. D'Haeseleer, Comparison of shell-and-tube with plate heat exchangers for the use in low-temperature organic Rankine cycles, Energy Conversion and Management 87 (2014) 227-237. doi:10.1016/j. enconman.2014.07.019.

[22] M. Imran, M. Usman, B.-S. Park, H.-J. Kim, D.-H. Lee, Multi-objective optimization of evaporator of organic Rankine cycle (ORC) for low temperature geothermal heat source, Applied Thermal Engineering 80 (2015) 1-9. doi:10.1016/j. applthermaleng. 2015.01.034.

[23] J. Xu, X. Luo, Y. Chen, S. Mo, Multi-criteria Design Optimization and Screening of Heat Exchangers for a Subcritical ORC, Energy Procedia 75 (2015) 1639-1645. doi:10.1016/j.egypro.2015.07.397.

[24] Mathworks, Matlab R2017b.

URL https://www.mathworks.com/help/matlab/

[25] J. K. Jensen, M. R. Kaern, T. S. Ommen, W. Brix, L. Reinholdt, B. Elmeegard, Effect of liquid/vapour maldistribution on the performance of plate heat exchanger evaporators, in: Proceedings of the 24th IIR International Congress of Refrigeration, 2015.

[26] T. Ommen, J. K. Jensen, W. B. Markussen, L. Reinholdt, B. Elmegaard, Technical and economic working domains of industrial heat pumps: Part 1 - Single stage vapour compression heat pumps, International Journal of Refrigeration 55 (2015) 168-182. doi:10.1016/j. ijrefrig.2015.02.011.

[27] E. Lemmon, M. Huber, M. McLinden, IST Standard Reference Database 23: Reference Fluid Thermodynamic and Transport PropertiesREFPROP, Version 9.1 (2013).

[28] I. H. Bell, J. Wronski, S. Quoilin, V. Lemort, Pure and pseudo-pure fluid thermophysical property evaluation and the open-source thermophysical property library coolprop, Industrial \& Engineering Chemistry Research 53 (6) (2014) 2498-2508. arXiv:http://pubs .acs . org/doi/pdf/10.1021/ie4033999, doi:10.1021/ie4033999.

[29] R. L. Amalfi, F. Vakili-Farahani, J. R. Thome, Flow boiling and frictional pressure gradients in plate heat exchangers . Part 2 : Comparison of literature methods to database and new prediction methods, International Journal of Refrigeration 61 (2016) 185-203. doi:10.1016/j. ijrefrig.2015.07.009.

[30] M. Kærn, A. Modi, J. Jensen, J. Andreasen, F. Haglind, An assessment of in-tube flow boiling correlations for ammonia-water mixtures and their influence on heat exchanger size, Applied Thermal Engineering 93 (2015) 623-638. doi:10.1016/j . applthermaleng.2015.09. 106. URL http://dx.doi.org/10.1016/j.applthermaleng.2015.09.106

[31] L. Silver, Gas cooling with aqueous condensation, Industrial Chemist and Chemical Manufacturer 23 (269) (1947) 380-386.

[32] K. Bell, M. Ghaly, An approximate generalized design method for multicomponent/partial condenser, AIChE Symposium Series 69 (1973) $72-79$.

[33] R. G. Sardesai, R. A. Shock, D. Butterworth, Heat and mass transfer in multicomponent condensation and boiling, Heat Transfer Engineering 3 (3-4) (1982) 104-114. doi:10.1080/01457638108939589.

[34] J. Thome, S. Shakir, A new correlation for nucleate pool boiling of aqueous mixtures, AIChE Symposium Series 83 (257) (1987) 46-51.

[35] M. Cooper, Heat flow rates in saturated nucleate pool boiling - a wide ranging examination using reduced properties, Advances in Heat Transfer 16 (1984) 59-156.

[36] H. Martin, A theoretical approach to predict the performance of chevron-type plate heat exchangers, Chemical Engineering and Processing 35 (4) (1996) 301-310. doi:10.1016/0255-2701(95)04129-X.

[37] F. Vakili-Farahani, R. L. Amalfi, J. R. Thome, Two-Phase Heat Transfer and Pressure Drop within Plate Heat Exchangers, in: J. R. Thome, J. Kim (Eds.), Encyclopedia of Two-Phase Heat Transfer and Flow II : Special topics and applications. Volume 2: Boiling Using Enhanced Surfaces, Plate Heat Exchangers and Two-Phase Devices. Chapter 4., World Scientific Publishing, 2015, Ch. Chapter 4, pp. 145-215. doi: https://doi.org/10.1142/9789814623285_0011. URL 10.1142/9789814623285_0011

[38] R. Shah, W. Focke, Plate heat exchangers and their design theory, in: R. Shah, E. Subbarao, R. Mashelkar (Eds.), Heat transfer equipment design, Hemisphere Publishing, Washington DC, 1988, pp. 227-254.

39] A. Bejan, G. Tsatsaronis, M. Moran, Thermal design and optimization, John Wiley and Sons, Inc., 1996. doi : 10.1016/S0140-7007 (97) 87632-3.

[40] Danish Energy Agency, Data, Tables, Statistics and Maps, Energy in Denmark (2015).

[41] J. R. Thome, Prediction of the mixture effect on boiling in vertical thermysyphon reboilers, Heat Transfer Engineering 10 (2) (1989) 29-38. doi:10.1080/01457638908939696.

715 [42] N. Metropolis, S. Ulam, The Monte Carlo Method, Journal of the americal statistical association 44 (247) (1949) 335-341.

[43] J. C. Helton, F. J. Davis, Latin hypercube sampling and the propagation of uncertainty in analyses of complex systems, Reliability Engineering and System Safety 81 (1) (2003) 23-69. arXiv:0511236, doi:10.1016/S0951-8320 (03) 00058-9.

[44] G. Sin, K. V. Gernaey, Data Handling and Parameter Estimation, in: D. B. Mark C.M. van Loosdrecht, P.H. Nielsen, C.M. Lopez-Vazquez (Ed.), Experimental Methods in Wastewater Treatment, iwa publis Edition, London, UK, 2016, pp. 201-234.

720 [45] R. Lockhart, R. Martinelli, Proposed correlation of data for isothermal two-phase, two-component flow in pipes, Chemical engineering progress 45 (1) (1949) 39-48.

[46] D. Chisholm, A Theoretical Basis for the Lockhart-Martinelli Correlation for Two-Phase Flow, International Journal of Heat and Mass 
Transfer 10 (18) (1967) 1767-1778. doi:http://dx.doi .org/10.1016/0017-9310(67)90047-6.

[47] B. Palm, J. Claesson, Plate Heat Exchangers: Calculation Methods for Single and Two-Phase Flow, Heat Transfer Engineering 27 (4) (2006) 88-98. doi: 10.1080/01457630500523949. 


\section{Highlights}

Paper ID: EGY-D-17-06250

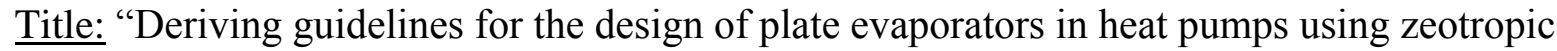
mixtures"

- Maximum allowable pressure drop do not lead to optimal heat exchanger design

- Refrigerant pressure drop negatively impacts both COP and NPV of heat pumps

- Different optimal pressure drop are found depending on the working fluid

- A HEX design guideline was derived by correlating non-dimensional parameters 